\title{
The Pathology of Experimental Aerosolized Monkeypox Virus Infection in Cynomolgus Monkeys (Macaca fascicularis)
}

\author{
Gary M. Zaucha, Peter B. Jahrling, Thomas W. Geisbert, James R. Swearengen, \\ and Lisa Hensley
}

Pathology Division (GMZ, TWG, LH), Headquarters (PBJ), and Veterinary Medicine Division (JRS), United States

Army Medical Research Institute of Infectious Diseases, Frederick, Maryland

SUMMARY: Cynomolgus monkeys (Macaca fascicularis) were exposed by fine-particle aerosol to lethal doses of monkeypox virus, Zaire strain. Death, attributable to fibrinonecrotic bronchopneumonia, occurred 9 to 17 days postexposure. Lower airway epithelium served as the principal target for primary infection. The relative degree of involvement among lymphoid tissues suggested that tonsil, mediastinal, and mandibular lymph nodes were also infected early in the course of the disease, and may have served as additional, although subordinate, sites of primary replication. The distribution of lesions was consistent with lymphatogenous spread to the mediastinal lymph nodes and systemic dissemination of the virus through a monocytic cell-associated viremia. This resulted in lesions affecting other lymph nodes, the thymus, spleen, skin, oral mucosa, gastrointestinal tract, and reproductive system. The mononuclear phagocyte/dendritic cell system was the principal target within lymphoid tissues and may also have provided the means of entry into other systemic sites. Hepatic involvement was uncommon. Lesions at all affected sites were characterized morphologically as necrotizing. Terminal deoxynucleotidyl transferase mediated deoxyuridine triphosphate nick-end labeling (TUNEL) staining of select lesions suggested that cell death within lymphoid and epithelial tissues was due in large part to apoptosis. Skin and mucosal surfaces of the respiratory and gastrointestinal tracts also exhibited variable proliferation of epithelial cells and subjacent fibroblasts. Epithelial intracytoplasmic inclusion bodies, consistent with Guarnieri bodies, were usually inconspicuous by light microscopy, but when present, were most readily apparent in the stratified squamous epithelium of the oral mucosa and epidermis. Multinucleated syncytial cells were also occasionally observed in the stratified squamous epithelium of the tongue, tonsil, and skin, and in the intestinal mucosa. Monkeypox virus antigen was readily demonstrated by immunohistochemistry using anti-vaccinia mouse polyclonal antibodies as well as anti-monkeypox rabbit polyclonal antibodies. Detectable poxviral antigen was limited to sites exhibiting obvious morphologic involvement and was most prominent within epithelial cells, macrophages, dendritic cells, and fibroblasts of affected tissues. The presence of poxviral antigen, as determined by immunohistochemistry, correlated with ultrastructural identification of replicating virus. Concurrent bacterial septicemia, present in one monkey, was associated with increased dissemination of the virus to the liver, spleen, and bone marrow and resulted in a more rapidly fatal clinical course. (Lab Invest 2001, 81:1581-1600).

\begin{abstract}
$M$ onkeypox virus, an orthopoxvirus closely related to variola, occurs as an enzootic disease in rural rainforest villages of central and western Africa (Arita et al, 1985). Based on serologic surveys and virus isolation, wild squirrels (Funisciurus anerythrus and Heliosciurus rufobrachium) were implicated as the most probable viral reservoir (Khodakevich et al, 1987), whereas nonhuman primates, although susceptible to infection, are not considered to represent a significant source for human exposure (Arita et al, 1972; Janseghers et al, 1984).

Although primary monkeypox infection is generally thought to be acquired through direct cutaneous or
\end{abstract}

Received May 2, 2001.

The views, opinions, andlor findings contained herein are those of the authors and should not be construed as an official Department of the Army position, policy, or decision unless so designated by other documentation. Address reprint requests to: LTC Gary M. Zaucha, 503 Robert Grant Avenue, Silver Spring, MD 20910-7500. E-mail: gary.zaucha@na.amedd. army.mi mucosal exposure to infected animals (Arita et al, 1985; Breman et al, 1980; Jezek et al, 1988; Lourie et al, 1972), the aerosol route of exposure plays a significant role in secondary transmission (Fenner, 1996) and is considered to be the usual natural route of transmission for smallpox in humans (Arita and Henderson, 1968; Blank and Rake, 1955; Hahon, 1961; Westwood et al, 1966). Additionally, orthopoxviruses are recognized as potential biological warfare or terrorist threat agents (Breman and Henderson, 1998; Franz et al, 1997). Aerosol doses under such conditions could far exceed those of natural transmission.

The epidemiology of monkeypox also appears to be changing, exacerbating the potential for sustained outbreaks among an increasingly susceptible human population. Of 155 cases reported from 1970 to 1983 , $80 \%$ were believed to have occurred as the result of direct transmission from an animal reservoir to the human host (Arita et al, 1985). Secondary transmission accounted for $24 \%$ of 103 cases surveyed from 1984 to 1986 (Marennikova et al, 1989). Previous estimates 
of the secondary attack rate for monkeypox among susceptible contacts range from as low as 3.3\% to as high as 15\% (Arita et al, 1985; Breman et al, 1977, 1980; Heymann et al, 1998), compared with the $25 \%$ to $45 \%$ secondary attack rate for smallpox (Breman et al, 1977, 1980). The low rate of secondary transmission may have limited the opportunity for sustained monkeypox infection among humans, and the disease occurred as self-limiting outbreaks of sporadic incidence. Current evidence, however, suggests an increased risk for secondary person-to-person transmission (Anonymous, 1997a, 1997b, 1998; Cohen, 1997; Heymann et al, 1998; Mukinda et al, 1997). The most recent outbreak of monkeypox in the Democratic Republic of the Congo (former Zaire) was the largest cluster of human monkeypox cases ever reported. Preliminary estimates of those cases were considered to have been the result of secondary transmission range up to $78 \%$ (Anonymous, 1997a; Heymann et al, 1998; Mukinda et al, 1997), with a secondary attack rate of $23 \%$ among close susceptible contacts (Heymann et al, 1998). These estimates may be revised downward, however, as evidence of simultaneous varicella infection in the same geographic region is evaluated (Heymann et al, 1998).

With the eradication of smallpox and widespread discontinuation of vaccinia vaccination, monkeypox has re-emerged as a human health threat (Anonymous, 1997a, 1997c, 1998; Arita et al, 1985; Cohen, 1997; Heymann et al, 1998; Mukinda et al, 1997). Although vaccinia vaccination protects against monkeypox, the risk of adverse effects warrants careful consideration before the vaccine is reintroduced into a population that may be immunocompromised because of a high incidence of HIV infection (Anonymous, 1997a, 1997c; Heymann et al, 1998; McConnell et al, 1964).

The clinical manifestations of monkeypox in humans, and their similarities to those of smallpox, are well documented (Arita et al, 1985; Breman et al, 1977, 1980; Foster et al, 1972; Janseghers et al, 1984; Jezek et al, 1987; Stagles et al, 1985). Monkeypox in nonhuman primates is also similar clinically (Cho and Wenner, 1973; Wenner et al, 1968, 1969b) and may serve as an animal model of both monkeypox and smallpox infection in humans. This study describes the pathologic findings in cynomolgus monkeys lethally exposed to aerosolized monkeypox virus.

\section{Results}

\section{Clinical Findings}

All monkeys appeared clinically normal on Day 0 of the study. Monkeys began to show evidence of exanthema, enanthema, mild anorexia, fever, cough, and nasal discharge on Days 6 and 7 postexposure. Dyspnea, noted as early as Day 8 postexposure, was evident in all animals by Day 10. By Days 9 and 10, all animals had exanthema and enanthema, were depressed and severely anorectic, and showed signs of weakness. Clinical signs progressed until the animals died naturally or were killed 9 to 17 days postexposure (mean 11.7 days). There was no correlation of inhaled dose to survival time. Leukocytosis (absolute and relative monocytosis) developed with the onset of clinical signs on Day 6. There were no trends detected in clinical chemistry data. Virus was first isolated from buffy coat cells of one of eight animals tested on Day 6. Nine of 11 animals were positive on Day 9, and 2 of 7 remained positive on Days 12 or 13 . There was no cell-free viremia detected at any time.

\section{Necropsy Findings}

Principal gross necropsy findings are presented in Table 1. All deaths were attributed to bronchopneumonia, although secondary bacterial septicemia was considered to be a contributing factor in one animal. Lungs were heavy and congested and failed to collapse. A dark red, lobular, mottled pattern of edema, atelectasis, and necrosis was distributed throughout all lung lobes (Fig. 1A). Occasionally, there was fibrinous pleuritis with pleural adhesions and multifocal, white, plaque-like thickenings of the visceral pleura. We observed a clear pericardial effusion in two monkeys.

Dermatitis, present in all monkeys, varied from barely detectable, single, small papules to extensive involvement primarily affecting the inguinal, ventral abdominal, ventral thoracic, perineal, and facial regions (Fig. 1, B and C). Palmar surfaces of the hands and plantar surfaces of the feet were only occasionally involved. The extent of involvement and the stage of skin lesion development noted at necropsy exhibited a positive correlation with the number of days elapsed since initial onset of the lesions was noted clinically. In animals necropsied 1 to 2 days after onset of exanthema, lesions were generally minimal in extent and were in the papular stage, appearing as pale tan to white, slightly raised foci, 2 to $4 \mathrm{~mm}$ in diameter. At 3 to 5 days post onset, lesion distribution was charac-

Table 1. Principal Gross Pathologic Findings in Monkeys Infected with Monkeypox Virus by Inhalation

\begin{tabular}{lc}
\hline \multicolumn{1}{c}{ Gross findings } & $\begin{array}{c}\text { Incidence } \\
(\mathrm{n}=15)\end{array}$ \\
\hline Respiratory system & \\
Bronchopneumonia & 15 \\
Pleuritis & 3 \\
Skin & \\
$\quad$ Dermatitis & 15 \\
Oral cavity & \\
Glossitis & 10 \\
Stomatitis & 10 \\
Gingivitis & 7 \\
Cheilitis & 5 \\
Gastrointestinal tract & \\
Colitis & 9 \\
Gastritis & 4 \\
Lymphoid system & \\
Peripheral lymphadenopathy & 5 \\
\hline
\end{tabular}



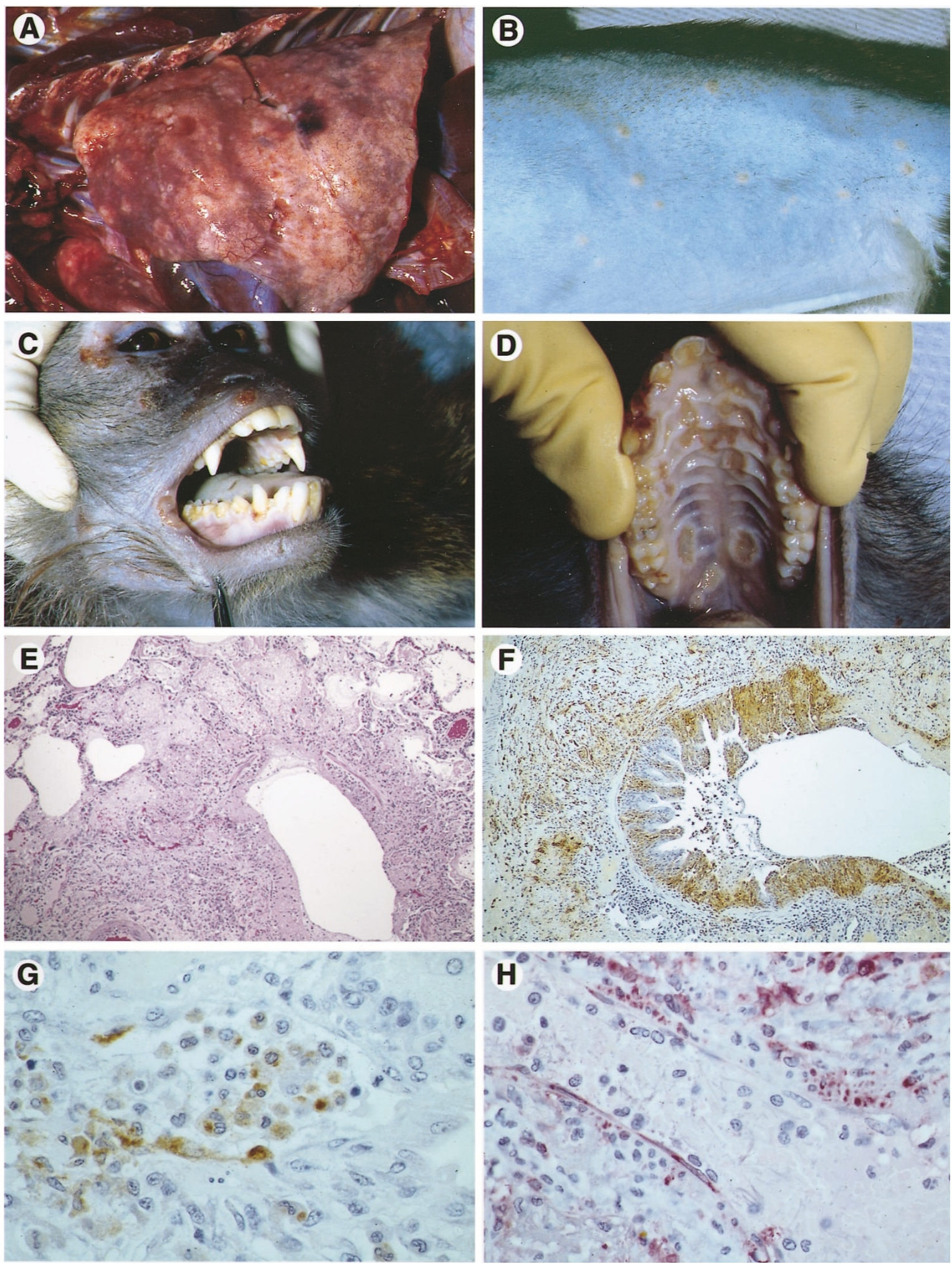

\section{Figure 1.}

Gross lesions from monkeys exposed to lethal aerosol doses of monkeypox virus (A-D). Necrotizing bronchopneumonia and fibrinous pleuritis (A). Papulovesicular dermatitis, lateral abdominal region (B). Facial exanthema, ulcerative cheilitis, and gingivitis (C). Ulcerative stomatitis (D). Lung, histopathology (E-H). There is complete necrosis of bronchial epithelium, with expansion of the interstitium by edema, inflammatory cells, and proliferating fibroblasts (E). Alveoli contain fibrin admixed with inflammatory cells, necrotic cellular debris, and edema. The bronchial epithelium is intensely positive for poxviral antigen (F). Lesser amounts of antigen are evident in mucosal gland epithelium and hyperplastic peribronchial fibroblasts. Lymphatic endothelium, intralymphatic monocytic cells (G), vascular smooth muscle, and endothelial cells of a bronchial artery $(\mathrm{H})$ are also positive for poxviral antigen (hematoxylin-eosin, original magnification, $\times 25$ [E]; immunoperoxidase (IP0), $\times 25[\mathrm{~F}]$ and $\times 150[\mathrm{G}]$; streptavidin alkaline-phosphatase (SAAP), $\times 150[\mathrm{H}])$. 
terized as mild. Papules were accompanied by 1 to 2 $\mathrm{mm}$ vesicles. Vesicle formation, however, was not prominent grossly. In the majority of instances, vesicles were ruptured and covered by small amounts of dried encrusted material. At 6 to 9 days after onset, lesion distribution was moderate to marked. The centers of the papules were depressed and covered by a dark red eschar.

Oral lesions occurred in $73 \%$ of the animals. The dorsal surfaces of the tongue and hard palate (Fig. 1D) were most commonly involved. Lesions presented as variably sized, depressed, reddened foci of necrosis, erosion, or ulceration, surrounded by pale tan to white, slightly raised margins of intact epithelium. Similar, although less extensive, lesions occurred on the buccal gingiva along the gumline. Ulcerative cheilitis occurred most commonly at the commissures of the mouth (Fig. 1C). We noted papulovesicular pharyngitis in one animal.

Gastrointestinal lesions, although relatively minor, were commonly observed. The distal colon or rectum was affected most frequently. Typically, there were several 2 to $3 \mathrm{~mm}$ raised foci with umbilicated necrotic centers on the mucosal surface. We observed a similar lesion in the cecum of one monkey. Gastritis occurred as white, slightly raised 2 to $4 \mathrm{~mm}$ foci of necrosis in the squamous portion of the stomach.

With the exception of lymph node congestion and mild peripheral lymphadenopathy, lymphoid lesions attributable to monkeypox were not detected grossly. We observed splenomegaly in one monkey, which we attributed to concurrent bacterial septicemia. Petechiae at the base of the heart, also observed in that animal, were attributed to septicemia as well.

\section{Histopathologic, Immunohistochemical, and Ultrastructural Findings}

The principal histopathologic findings are presented in Table 2.

Respiratory System. All monkeys developed fibrinonecrotic bronchopneumonia. There was extensive necrosis of bronchial and bronchiolar epithelium, with filling of airways by edema, fibrin, macrophages, degenerate neutrophils, and necrotic cellular debris (Fig. $1 E)$. A zone of necrotic alveoli filled with similar exudate frequently surrounded affected airways. There was hyperplasia of bronchial epithelial cells, peribronchovascular fibroblasts, and type II pneumocytes. Peripheral alveoli were often flooded with edema fluid. The peribronchovascular interstitium was expanded by edema and dilated lymphatics containing fibrin, monocytic cells, and karyorrhectic debris. There was necrotizing vasculitis in association with necrotic airways. The pleura was occasionally thickened by edema, mixed inflammatory cells, hyperplastic fibroblasts, and hypertrophied mesothelial cells.

Degenerate and necrotic airway epithelium and proliferating fibroblasts in the surrounding interstitium were strongly positive by immunohistochemistry (IHC) for poxviral antigen (Fig. 1F). Antigen was not associated with adjacent hyperplastic and normal-appearing
Table 2. Principal Histopathologic Findings in Monkeys Infected with Monkeypox Virus by Inhalation

\begin{tabular}{|c|c|}
\hline $\begin{array}{l}\text { Histopathologic } \\
\text { findings }\end{array}$ & Incidence ${ }^{a}$ \\
\hline \multicolumn{2}{|l|}{ Respiratory system } \\
\hline Bronchopneumonia & 15 \\
\hline Tracheitis & 14 \\
\hline Laryngitis & 13 \\
\hline Mediastinitis & 14 \\
\hline \multicolumn{2}{|l|}{ Lymphoid system } \\
\hline \multicolumn{2}{|l|}{ Lymphadenitis } \\
\hline Mediastinal & 12 \\
\hline Mandibular & 13 \\
\hline Axillary/Inguinal & 8 \\
\hline Mesenteric & 6 \\
\hline Splenitis & 11 \\
\hline Tonsillitis & $12(n=14)$ \\
\hline Thymitis & $9(n=13)$ \\
\hline \multicolumn{2}{|l|}{ Oral cavity } \\
\hline Glossitis & 12 \\
\hline Cheilitis & $9^{b}$ \\
\hline Stomatitis & $8^{c}$ \\
\hline Gingivitis & 7 \\
\hline \multicolumn{2}{|l|}{ Skin } \\
\hline Dermatitis & $11^{d}(\mathrm{n}=12)$ \\
\hline \multicolumn{2}{|l|}{ Gastrointestinal tract } \\
\hline Colitis & 11 \\
\hline Gastritis & 5 \\
\hline Typhlitis & 7 \\
\hline Ileitis & 3 \\
\hline Esophagitis & $1(n=14)$ \\
\hline \multicolumn{2}{|l|}{ Reproductive system } \\
\hline Oophoritis & $6(n=7)$ \\
\hline Metritis & $4(n=7)$ \\
\hline Vaginitis & $3(n=5)$ \\
\hline Orchitis & $2(n=8)$ \\
\hline Epididymitis & $1(n=8)$ \\
\hline \multicolumn{2}{|l|}{ Liver } \\
\hline Hepatitis & 3 \\
\hline $\begin{array}{l}{ }^{a} \text { The number of animals in which } \\
\text { unless otherwise indicated: } \mathrm{n}=15 \text {. } \\
{ }^{b} \text { One additional monkey was gros } \\
{ }^{c} \text { Two additional monkeys were } \mathrm{grc} \\
{ }^{d} \text { Four additional monkeys were gr }\end{array}$ & as examined hist \\
\hline
\end{tabular}

intact bronchial epithelium. Submucosal gland epithelium, macrophages, and to a lesser extent, alveolar pneumocytes, lymphatic endothelium, and intralymphatic monocytic cells (Fig. 1G) were also positive for poxviral antigen. We detected small amounts of antigen in bronchial smooth muscle cells subjacent to necrotic mucosa and in vascular smooth muscle cells and endothelium associated with vasculitis (Fig. $1 \mathrm{H}$ ). We detected poxviral antigen in mesothelial cells and subjacent fibroblasts within areas of pleuritis.

Ultrastructural examination of lung demonstrated that poxviral antigen detected by light microscopy indicated replicating virus. Naked viroplasm, sequential stages of virus particle development, and mature virions were identified in the cytoplasm of bronchial epithelial cells, type II pneumocytes (Fig. 2), fibro- 


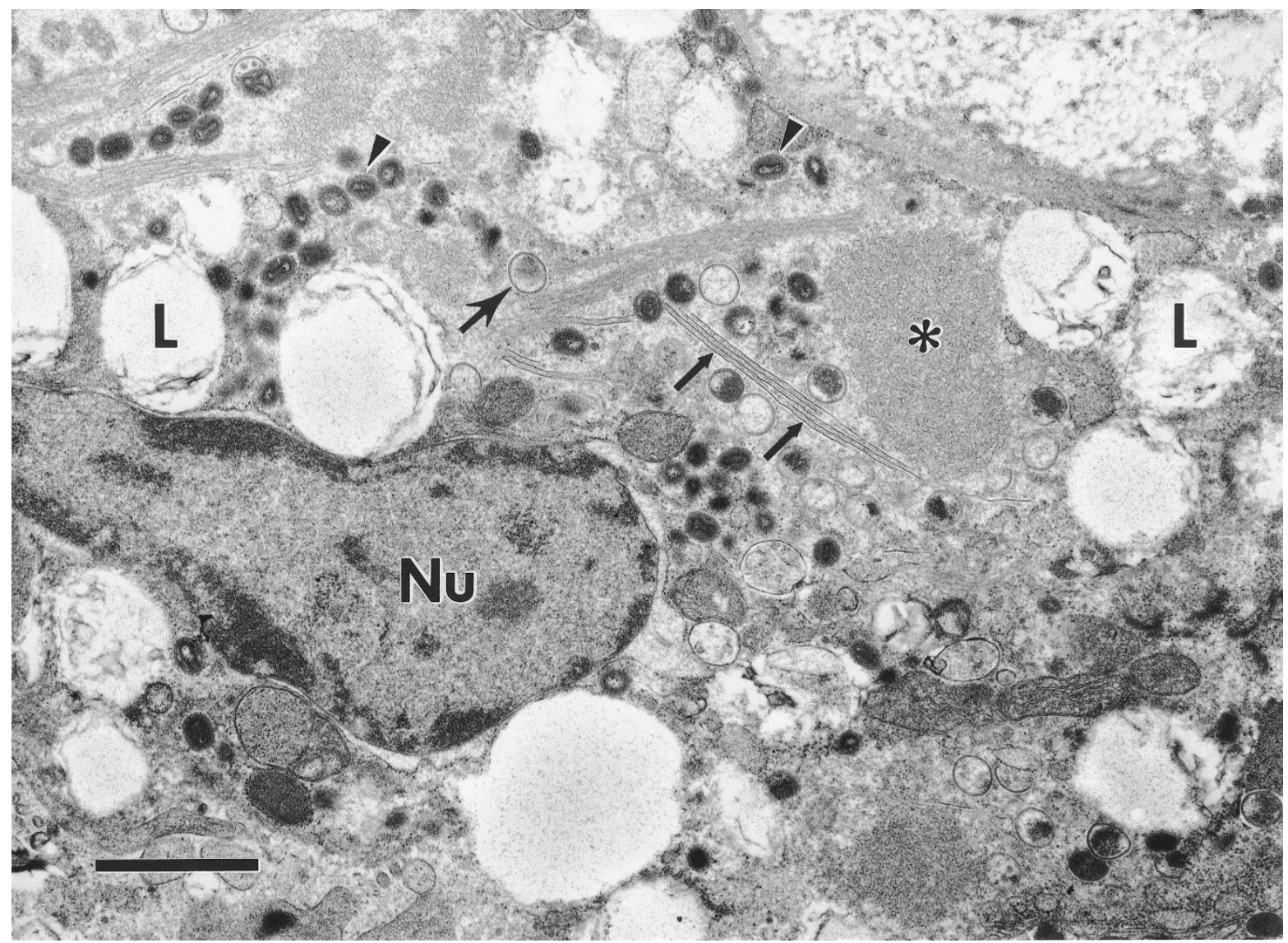

\section{Figure 2.}

Transmission electron micrograph (TEM) of lung. Note naked viroplasm (*), formative shells containing viroplasm (spearhead), mature virions (arrowheads), and lamellar structures (small arrows) in cytoplasm of type II pneumocyte. Degenerate lamellar bodies $(L)$, nucleus $(N u)$. Bar $=1.25 \mu \mathrm{m}$.

blasts, macrophages, and endothelial cells (Fig. 3). Cytoplasmic lamellar structures were also occasionally observed in association with virus replication.

Additional respiratory lesions included tracheitis, laryngitis, and mediastinitis. Upper airway lesions were morphologically similar to those in the bronchi. We detected poxviral antigen primarily within degenerate respiratory epithelium of the trachea and larynx, transitional and squamous laryngeal epithelium, and submucosal glandular epithelium. Small amounts of antigen were detected in fibroblasts underlying epithelial lesions. Mediastinitis occurred as an extension of mediastinal lymphadenitis and thymitis. Lesions tended to immediately surround affected lymphoid tissues and were characterized by proliferation of fibroblasts, necrosis of fibroadipose tissue, and infiltration by macrophages and neutrophils. Lymphatics were occasionally dilated and contained large numbers of monocytic cells. We detected poxviral antigen, primarily in fibroblasts, and to a lesser degree in macrophages, vascular and lymphatic endothelium, and monocytic cells within distended lymphatics.

Lymphoid Tissues. Necrotizing lymphadenitis occurred in all monkeys. Mediastinal and mandibular lymph nodes exhibited the most severe lesions (Fig. $4 \mathrm{~A})$; axillary, inguinal, and mesenteric lymph nodes were also involved. Mild lesions appeared as foci of necrosis within the superficial cortex, whereas severely affected mediastinal lymph nodes were completely necrotic. Subcapsular and medullary sinuses were dilated and contained large foamy macrophages and degenerate neutrophils.

Poxviral antigen was limited to necrotic cortical regions immediately subjacent to the subcapsular sinus of mildly affected nodes (Fig. 4B). Affected cell types were morphologically consistent with macrophages, dendritic cells, and fibroblast-like reticular cells. As lesions increased in severity, antigen became apparent within sinus lining cells, capsular fibroblasts, monocytic cells within the subcapsular sinuses, and follicular dendritic cells. Poxviral involvement extended along the reticular-cell network to involve deeper cortical regions (Fig. 4C) and dendritic cells or macrophages within the medulla (Fig. 4D). In mediastinal and mandibular lymph nodes with diffuse necrosis, antigen was distributed throughout all regions of the node and in a zone of proliferating fibroblasts in the surrounding interstitium.

Transmission electron microscopy of mediastinal lymph nodes revealed viral replication in macrophages (Fig. 5) and cells that we interpreted as reticular cells. Infected fibroblasts and endothelial cells were less common. Sinus lining cells also contained replicating virus, but the cell type could not be definitively deter- 


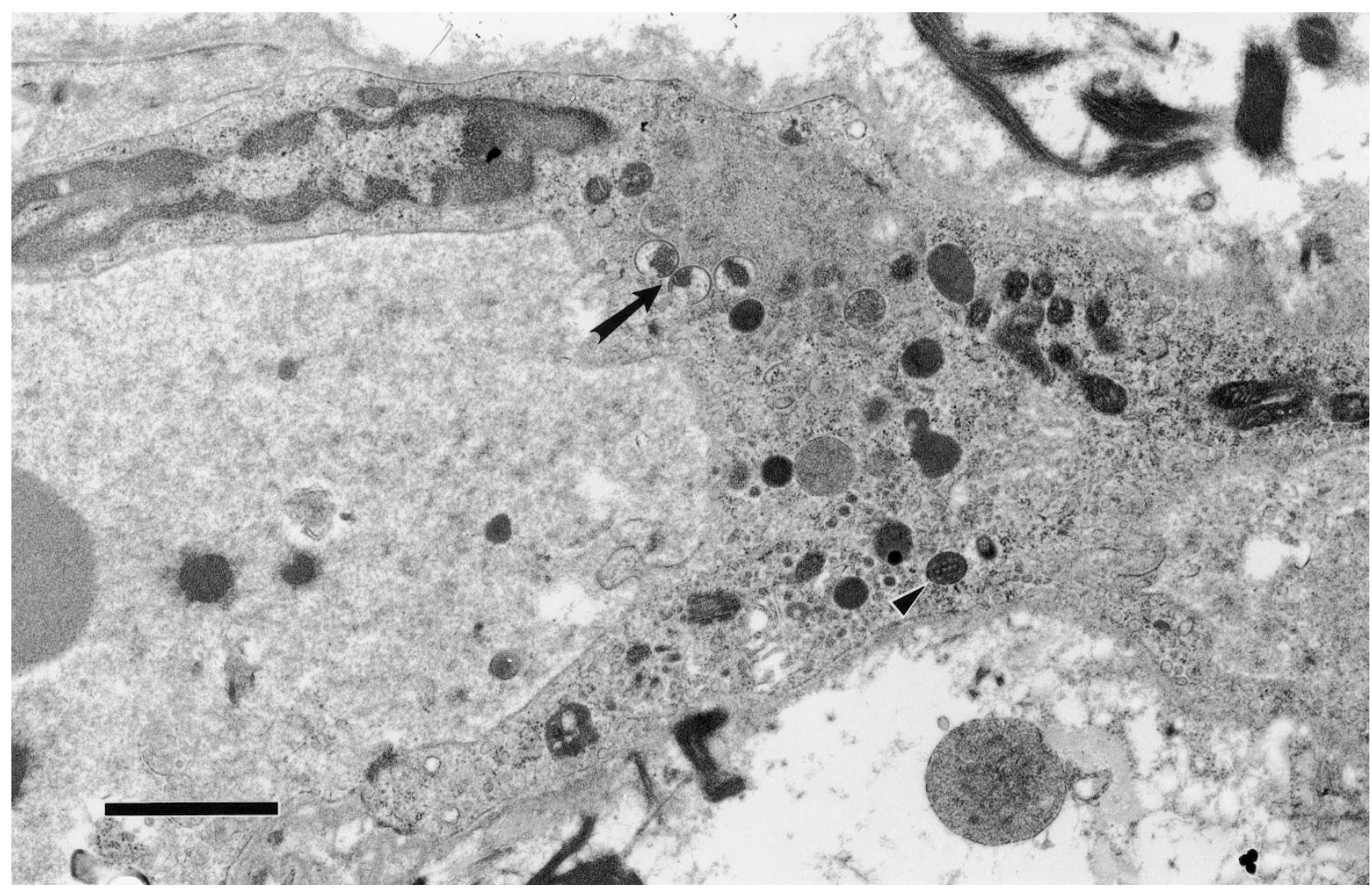

Figure 3.

TEM of lung. Note formative shells containing viroplasm (arrow) and mature virion (arrowhead) within cytoplasm of endothelial cell. Bar $=1.25 \mu \mathrm{m}$.

mined because of necrosis and architectural disruption. Nonviral tubuloreticular inclusions, typical of those associated with interferon production (Grimley et al, 1983), were evident occasionally in endothelial cells.

Splenitis occurred as foci of necrosis centered on lymphoid follicles, with infiltration by macrophages and neutrophils admixed with necrotic cellular debris. We noted lymphoid hyperplasia most commonly in the marginal zones and periarteriolar lymphoid sheaths, although germinal centers were also occasionally affected. Seven of the 11 affected spleens were positive for poxviral antigen by $\mathrm{IHC}$, and with two exceptions, antigen appeared to be limited to cells that we interpreted as macrophages or dendritic cells and fibroblast-like reticular cells within necrotic follicles (Fig. 4E) and within periarteriolar lymphoid sheaths. Antigen was generally not associated with hyperplastic regions. In one of the remaining immunoreactive spleens, we detected antigen within macrophages in the red pulp as well as in necrotic follicles. The other immunoreactive spleen was complicated by suppurative bacterial splenitis, and necrotic foci, as well as abundant poxviral antigen, were distributed throughout all regions of the spleen (Fig. 4F). Macrophages and dendritic cells within follicles and periarteriolar sheaths, fibroblasts, and numerous macrophages disseminated throughout the red pulp were strongly positive for poxviral antigen in this animal. Viral replication, as evidenced by developmental stages of viral particles, occurred in macrophages, reticular cells, fibroblast-like cells, cells interpreted as pericytes, and endothelial-like cells. There were also occasional gram-positive bacilli in the red pulp of this animal.

Tonsils, thymus, and gut-associated lymphoid tissues (GALT, see "Gastrointestinal System") were also affected. Tonsillitis consisted of areas of epithelial necrosis and ulceration, with hyperplasia of remaining adjacent epithelium and necrosis of underlying lymphoid follicles. Antigen was present within squamous epithelium, necrotic follicles, and fibroblasts.

Thymitis occurred as randomly scattered foci of necrosis. Poxviral antigen was present occasionally in macrophages unassociated with necrotic foci (Fig. $4 G)$. In mildly necrotizing thymic lesions, antigen was present within macrophages and dendritic cells. Antigen was distributed throughout dendritic cells of fully necrotic foci (Fig. 4H). Epithelial cells of Hassall's corpuscles appeared to become infected only secondarily. Ultrastructurally, poxvirus replication was seen in macrophages, reticular cells, and endothelial cells. Some cells contained cytoplasmic lamellar structures associated with poxvirus particles and viroplasm, as we noted in the lungs. Infected thymic epithelial cells could not be definitively identified.

Oral Mucosa. Oral epithelial lesions were similar morphologically to those of the skin (see "Skin and Adnexa") and were characterized by epithelial swelling, necrosis, ulceration, hyperplasia, indistinct intraepithelial cytoplasmic inclusion bodies (Guarnieri bodies), and multinucleated syncytial cells (Fig. 6A). The tongue, lips, hard palate, gingiva, and buccal mucosa were affected. We also commonly observed necrotizing sialadenitis of the labial salivary glands. We de- 

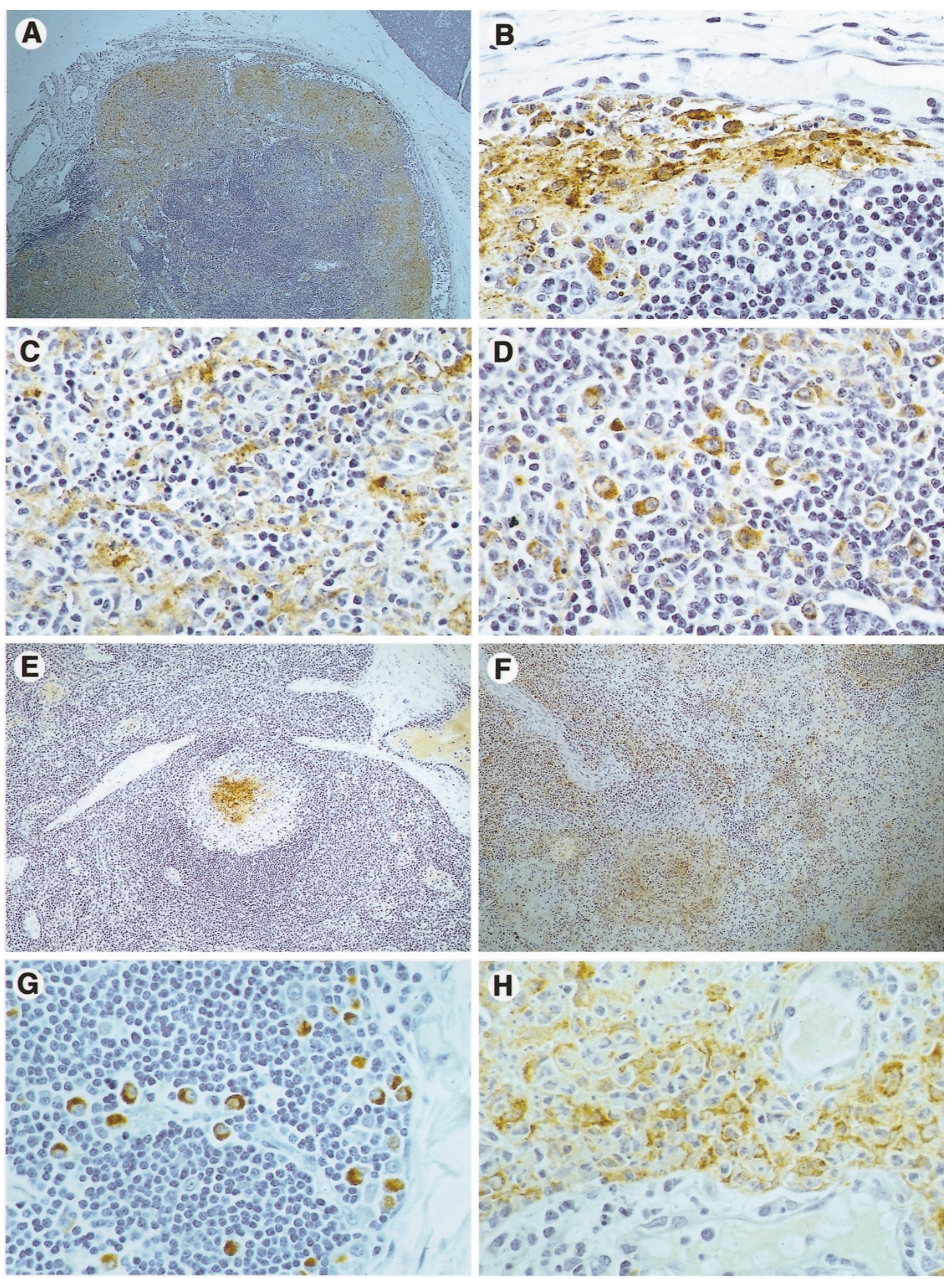

\section{Figure 4.}

Mandibular lymph node (A-D). In lymph nodes exhibiting advanced stages of necrosis, there is concentration of poxviral antigen within necrotic cortical regions, with lesser amounts of antigen within medullary cords (A). In mildly involved nodes, poxviral antigen is limited to fibroblast/dendritic cells immediately below the subcapsular sinus (B). As lesions progress in severity, poxviral immunoreactivity extends to deeper areas of the cortex through reticulum/dendritic cells (C). Macrophages and dendritic cells in the medulla are also involved in advanced stages (D). Spleen (E, F). Monkeypox virus antigen is concentrated in macrophages or dendritic cells of follicular germinal centers of uncomplicated cases $(E)$, whereas antigen is distributed throughout all regions of the spleen of a monkey with concurrent bacterial septicemia (F). Thymus (G, H). Poxviral antigen is evident within macrophages in an area of thymus not yet exhibiting obvious necrotic changes (G). Antigen is detected in dendritic cells in more advanced lesions (H) (IPO, original magnification, $\times 10[A], \times 150[B-D, G, H], \times 25[E, F])$. 


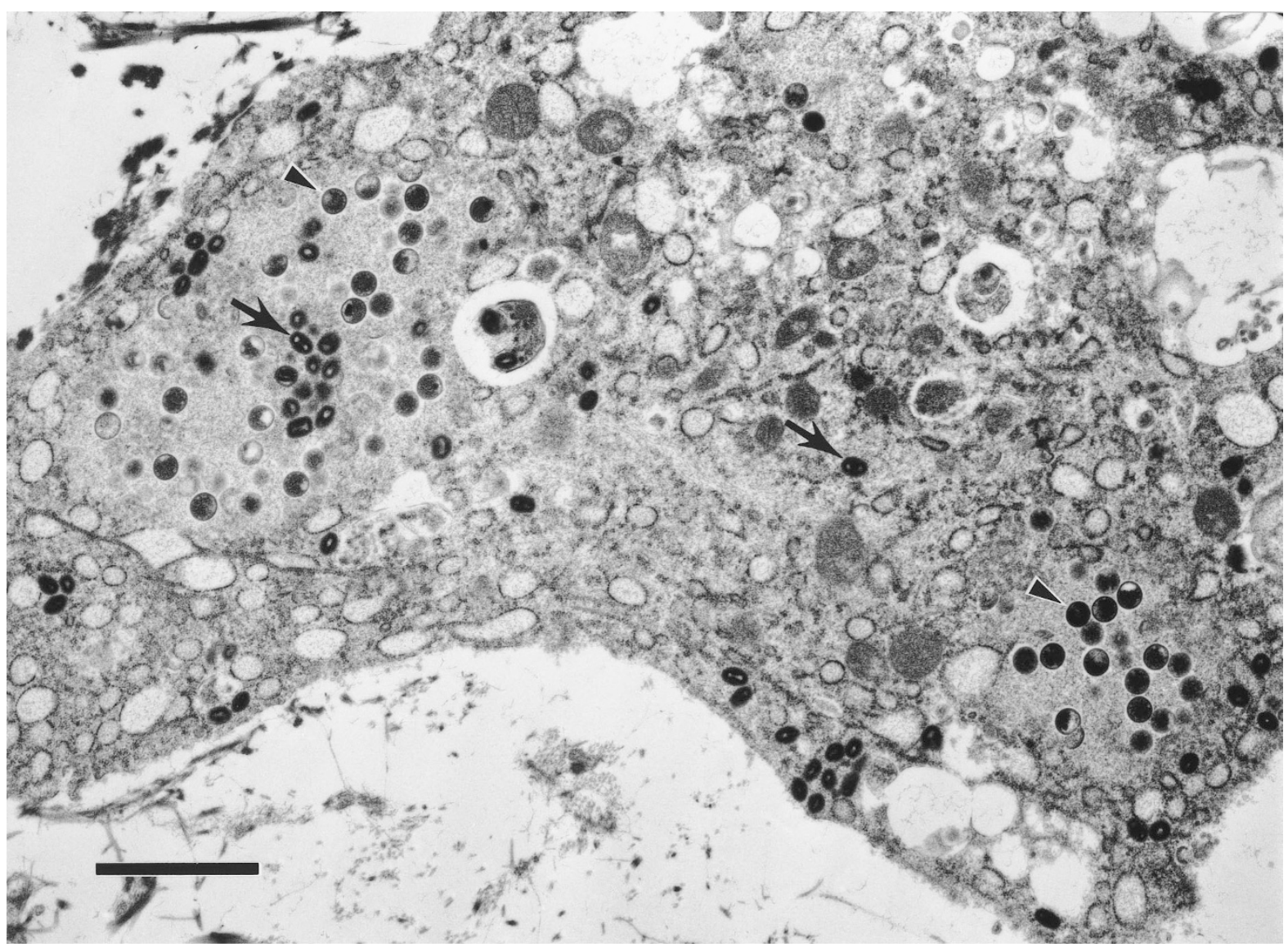

Figure 5 .

TEM of mediastinal lymph node. Tissue macrophage congested with formative shells containing viroplasm (arrowheads) and mature virions (spearheads). Bar = 1.9 $\mu \mathrm{m}$.

tected poxviral antigen by IHC within stratified squamous epithelium and dermal/submucosal fibroblasts of all affected tissues, in follicular, sebaceous, and salivary epithelium of the lip, and in salivary duct and glandular epithelium of the palate. Rarely, weakly immunopositive mononuclear cells were identified within the basal regions of as yet unaffected stratified squamous epithelium (Fig. 6B). Within mildly affected stratified squamous epithelium, poxviral antigen appeared in the basal regions and advanced superficially in more severe lesions (Fig. 6C). Inclusion bodies were variably positive by IHC.

Skin and Adnexa. Cutaneous lesions were characterized by epithelial hyperplasia, with necrosis most prominently in the stratum basale and deep stratum spinosum. There was infiltration of the epidermis by neutrophils admixed with necrotic cellular debris. At the margins of necrotic areas, severe intracellular edema of the stratum spinosum was common. Swollen epithelial cells gave way to the formation of intraepithelial vesicopustules containing neutrophils, eosinophilic fluid, and fibrin. In more advanced lesions, there was necrosis and inflammation of the superficial dermis and superficial layers of the stratum spinosum, leading to ulceration. Follicular and sebaceous epithelium were also affected, whereas apocrine glands were spared. Intraepithelial cytoplasmic inclusion bodies consistent with Guarnieri bodies were occasionally observed. There also were multinucleated syncytial cells within epithelial regions exhibiting moderate degenerative changes adjacent to areas of necrosis. Viral antigen was detected most prominently within squamous epithelium of the epidermis and less prominently in follicular epithelium, sebaceous glands, and dermal fibroblasts. Minimal antigen was detected in apocrine glandular epithelium of two monkeys. Ultrastructural examination of grossly affected skin revealed poxviral replication in keratinocytes of the basal cell layer up through the granular cell layer of the epidermis. Replicating virus was detected to a lesser extent in dermal fibroblasts. Intracytoplasmic lamellar structures were occasionally associated with viral replication in keratinocytes. In the epidermis, there was widening of intercellular spaces and disruption of intercellular junctions, with formation of clefts containing infected keratinocytes, fibrin, neutrophils, and necrotic debris. Dissociated keratinocytes often developed a microvillous border. Mature viral particles were occasionally seen free within the widened intercellular spaces of the epidermis.

Gastrointestinal System. Gastrointestinal lesions involved the distal colon or rectum, gastric cardia, ileum, cecum, and esophagus. With the exception of the esophagus, lesions were characterized by mucosal 

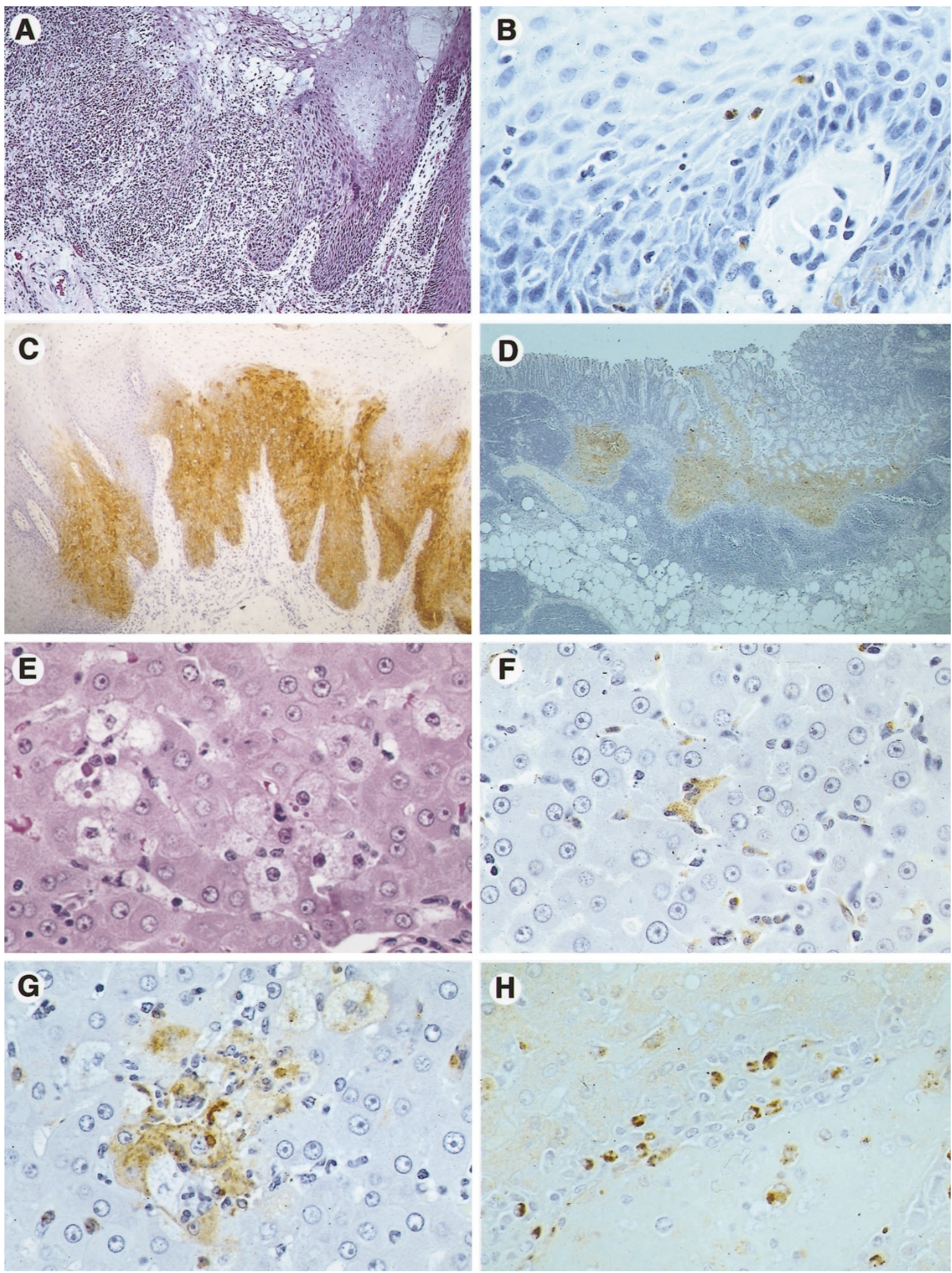

\section{Figure 6.}

Tongue $(A-C)$. There is epithelial cell swelling, vesicle formation, hyperplasia, and syncytia, with dense submucosal inflammatory infiltrates in mature oral lesions (A). In areas of minimal involvement, immunopositive monocytic cells are rarely seen within as-yet-unaffected epithelium (B). As lesions increase in severity, there is progression of poxviral antigen from basilar to more superficial regions of affected epithelium (C). with sparing of the submucosa. Colon (D). Note extensive necrosis and poxviral antigen immunoreactivity of the gut-associated lymphoid tissue, with relatively mild involvement of overlying mucosa. Liver (E-H). Note swollen hepatocytes with intracytoplasmic inclusion bodies (E). Kupffer cells are poxviral antigen-positive before hepatocytes are affected (F). Swollen hepatocytes within more advanced lesions are also positive for poxvirus $(\mathrm{G})$. Immunopositive portal macrophages and circulating monocytic cells were evident in one monkey (H) (hematoxylin-eosin, original magnification, $\times 25[\mathrm{~A}], \times 150[\mathrm{E}] ; \mathrm{IPO}, \times 150[\mathrm{~B}, \mathrm{~F}-\mathrm{H}], \times 25[\mathrm{C}], \times 10[\mathrm{D}])$. 
necrosis that had progressed to erosion or ulceration in more advanced lesions, proliferation of underlying fibroblasts, and infiltration by low numbers of neutrophils and macrophages. Necrosis of the GALT appeared to precede mucosal involvement in many of the lesions (Fig. 6D). There were very few syncytia. Antigen was detected in glandular or crypt epithelium of the stomach, colon, cecum, and ileum; in stratified squamous epithelium of the gastric cardia; in fibroblasts in the submucosa or lamina propria of the cecum, ileum, stomach, and colon; and in macrophages or dendritic cells within associated GALT. As described for oral mucosa, there were weakly immunopositive mononuclear cells rarely in association with otherwise unaffected stratified squamous epithelium of the stomach. Minimal antigen was present within smooth muscle of the muscularis mucosa of more severely affected sections of colon, cecum, and stomach. Esophagitis, observed only in one animal, was characterized by minimal degeneration of esophageal epithelium, and infiltration of the underlying lamina propria by low numbers of lymphocytes. In this monkey, poxviral antigen was limited to the deep layers of squamous epithelium.

Reproductive System. Histopathologic lesions of the reproductive system included vaginitis, oophoritis, metritis, epididymitis, and orchitis. Vaginitis and superficial uterine lesions were similar to epithelial lesions in other organ systems, with epithelial degeneration, necrosis, and hyperplasia. There were also necrotic foci in the uterine stroma and myometrium. Antigen was detected in vaginal and uterine epithelium, uterine stroma, myometrium, and submucosal fibroblasts. Ovaries of affected animals exhibited foci of necrosis involving secondary follicles and stroma, with antigen present in granulosa and thecal cells of follicles and in stromal spindle cells. Mild necrotizing lesions of the testes and epididymis contained viral antigen within interstitial spindle cells of both structures and within tubular epithelium of the epididymis.

Liver. Hepatitis occurred in two monkeys that died on Days 13 and 14 postexposure and in the single monkey with concurrent bacterial septicemia that died on Day 9. With the exception of the animal with bacterial infection, there was no histologic or immunohistochemical evidence of monkeypox-associated hepatic changes in any of the 10 monkeys that died before Day 13. Hepatocellular hyperplasia, as evidenced by increased numbers of mitotic figures, occurred in the five monkeys that died on Days 13 to 17; however, poxviral antigen was not detected in the livers of those animals in the absence of morphologic evidence of hepatitis.

The liver of the most severely affected animal (Day 14) contained numerous disseminated foci of swollen hepatocytes with flocculent to vacuolated cytoplasm and amphophilic to basophilic cytoplasmic inclusion bodies (Fig. 6E). Single cell necrosis was common, necrotic cellular debris was often present within sinusoids, and there was a subjective increase in Kupffer cell numbers as well as infiltration of sinusoids by neutrophils. IHC demonstrated abundant virus antigen within Kupffer cells disseminated throughout the liver (Fig. 6F) and, to a lesser extent, within swollen hepatocytes (Fig. 6G). There was ultrastructural evidence of viral replication in vacuolated hepatocytes and Kupffer cells (Fig. 7). Cytoplasmic inclusions identified by light microscopy were composed of electron-dense, fibrous-to-granular aggregates of material we interpreted as viroplasm, associated with immature viral particles. There were numerous degenerate Kupffer cells, and sinusoids were sometimes congested with cellular debris and fibrin. Infected endothelial cells could not be definitively identified. Nonviral tubuloreticular inclusions were occasionally seen in sinusoidal endothelial cells. In the monkey that died on Day 13, there was minimal hepatocellular degeneration and necrosis with virus antigen limited to hepatocytes and Kupffer cells of the few small degenerate foci.

The remaining monkey, diagnosed with concurrent bacterial septicemia, had what we interpreted as preexisting, subacute-to-chronic portal hepatitis. Lymphocytes, macrophages, and eosinophils infiltrated portal tracts. There were increased numbers of Kupffer cells, circulating monocytic and polymorphonuclear leukocytes, necrotic mononuclear cells, fibrin thrombi, and bacterial emboli within sinusoids throughout the liver. Hepatocytes were hypertrophied; however, hepatocellular degeneration was minimal. Kupffer cells, macrophages within portal tracts, and occasional circulating monocytic cells within sinusoids and portal veins were strongly positive for poxviral antigen (Fig. 6H). Small, scattered foci of hepatocytes were mildly immunoreactive. In addition to the ultrastructural features described for the Day 14 monkey above, virus-infected circulating monocytic cells and Kupffer cells containing gram-positive bacilli were identified in this monkey.

Bone Marrow. We observed virus-induced myelitis in the single monkey, which also had a concurrent bacterial infection. Although poxviral antigen was prominent within macrophages and dendritic cells in the affected bone marrow, bacteria were also evident. Poxviral replication was seen ultrastructurally in macrophages, reticular (stromal) cells, and a few cells interpreted as monocytes. Gram-positive bacilli were also present in some fields (Fig. 8). There was no evidence of myelitis or poxviral antigen in the bone marrow of the remaining 14 monkeys.

Additional Findings. Infrequent findings attributed to monkeypox were necrotizing conjunctivitis and thyroiditis. We detected antigen within conjunctival epithelial cells and fibroblasts. Because of the limited extent of the thyroid lesion, insufficient material was available for IHC.

As noted previously, we believe bacterial septicemia and terminal DIC contributed to the death of one monkey (animal no. 289). Although samples for bacterial culture were not obtained at the time of necropsy, histopathologic examination revealed evidence of septicemia and DIC, which included the presence of gram-positive bacilli in addition to poxviral antigen associated with lesions of the spleen, lymph nodes, 


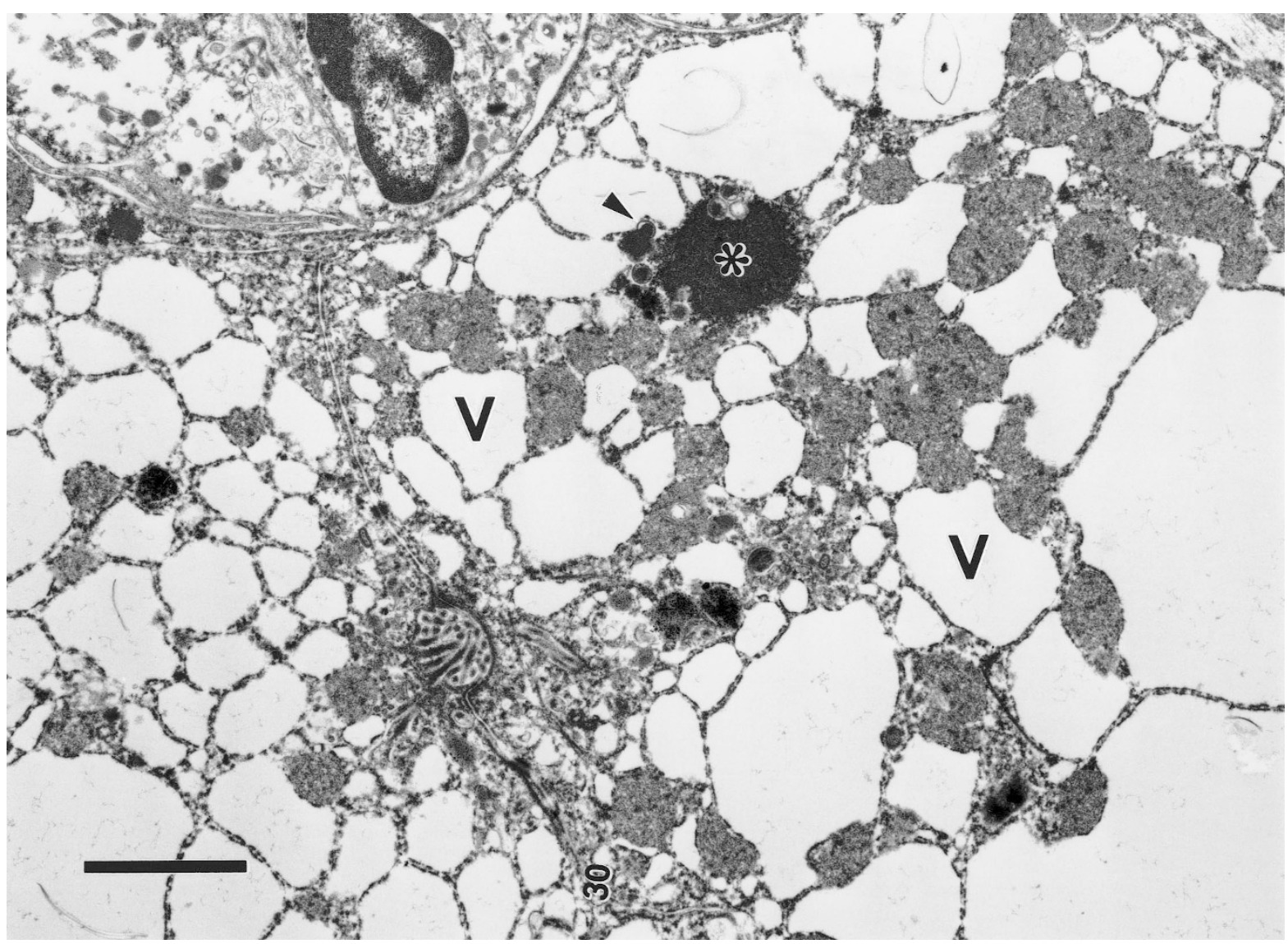

Figure 7.

TEM of liver. Note dense viroplasm (*) and associated progeny viral particles (arrowhead) in cytoplasm of hepatocyte. Vacuolation $(V)$ of cytoplasm was striking. Bar $=2.5 \mu \mathrm{m}$.

liver, and bone marrow; minimal bacterial encephalitis; acute renal tubular necrosis; and fibrin thrombi with embolic bacilli in multiple tissues.

No lesions attributable to monkeypox and no immunohistochemical evidence of poxviral antigen were seen in heart, skeletal muscle, kidney, urinary bladder, mammary gland, parathyroid gland, pituitary gland, adrenal gland, prostate gland, seminal vesicle, gallbladder, pancreas, duodenum, jejunum, peripheral nerve (sciatic and brachial), eye, or brain.

\section{TUNEL Staining}

Results of terminal deoxynucleotidyl transferase mediated deoxyuridine triphosphate nick-end labeling (TUNEL) of representative lesions suggested that necrotic features observed on hematoxylin and eosinstained tissue sections were due in large part to apoptosis (Fig. 9). Mononuclear cells within necrotic foci of splenic follicles, GALT (colon), lymph nodes, and thymus, and necrotic epithelial cells of the trachea, bronchi, and lip were strongly positive. Individual mononuclear cells scattered throughout the splenic red pulp were also positive, as were cells within the interstitium surrounding necrotizing lesions of the tissues listed above. Lymph node sinus histiocytes frequently contained positive-staining apoptotic bodies within the cytoplasm.

\section{Virus Isolation}

Results of virus isolation from tissues obtained at necropsy and a correlation with morphologic involvement and immunohistochemistry are presented in Table 3. High viral titers were consistently obtained from lung and spleen. With one exception, lung titers were generally several logs greater than those obtained from spleen. Virus was isolated from liver, kidney, and adrenal gland only sporadically.

\section{Discussion}

The principal distinguishing feature of lethal infection by aerosolized monkeypox virus in cynomolgus monkeys was severe fibrinonecrotic bronchopneumonia. A high incidence of bronchopneumonia was reported for fatal cases of monkeypox in humans (Janseghers et al, 1984; Jezek et al, 1987), and bronchopneumonia was reported often as a feature of smallpox ( Blank and Rake, 1955; Bras, 1952; Councilman et al, 1904). Cough is also a common clinical feature among nonfatal cases of monkeypox in humans (Jezek et al, 1987, 1988). Lancaster et al (1966) described pulmonary lesions in monkeys exposed by inhalation to variola that were essentially identical with those seen in our study of monkeypox. Lancaster's findings, however, differed from our own in that lesions were 


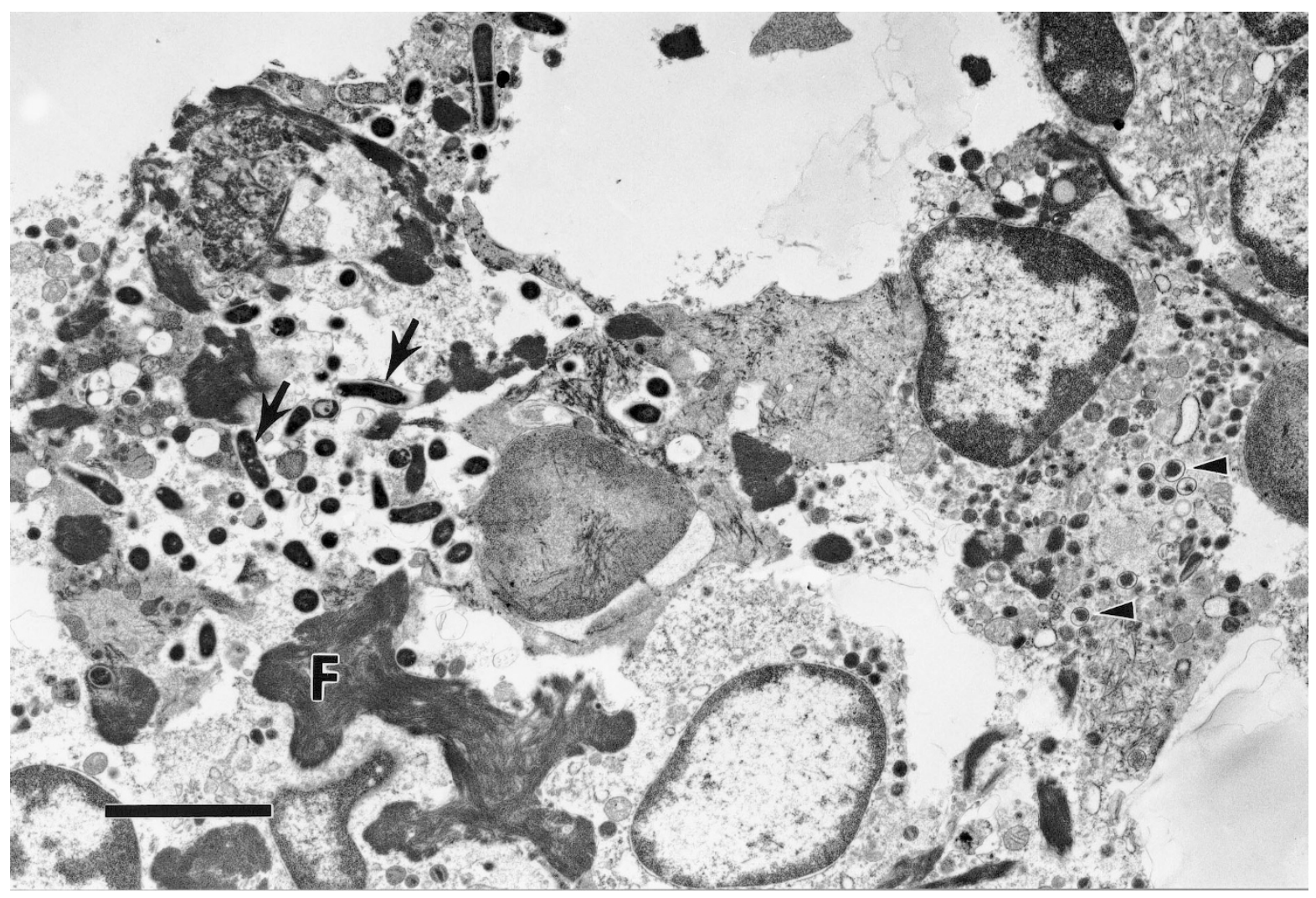

Figure 8.

TEM of femoral bone marrow. Formative monkeypox virions containing viroplasm (arrowheads) are present in cytoplasm of a stromal cell. Also, note adjacent gram-positive bacteria (spearheads) associated with cellular debris and fibrin deposits $(F)$. Bar $=3.0 \mu \mathrm{m}$.

limited to the lungs, and systemic dissemination apparently did not occur. This is in contrast to reports of experimental monkeypox administered in routes other than aerosol and the majority of spontaneously occurring outbreaks of monkeypox in nonhuman primates, in which the disease was often self-limiting and pneumonia or clinical signs of pulmonary involvement were uncommon (Arita and Henderson, 1968; Crandell et al, 1969; Gispen et al, 1967; Gough et al, 1982; Hahon, 1961; Hall and McNulty, 1967; Heberling and Kalter, 1971; Prier and Sauer, 1960; Sauer et al, 1960; von Magnus et al, 1959; Wenner et al, 1968, 1969a). The consistently severe pneumonia seen in our study may be attributed to the viral strain and delivery system we used. The strain was originally isolated from a fatal human case of monkeypox. Preliminary aerosol trials in cynomolgus monkeys indicated that this strain was significantly more virulent than the reference Copenhagen strain, which failed to result in mortalities under identical conditions of exposure (PB Jahrling, unpublished data). The high-dose, fine-particle aerosol used in this study also resulted in the delivery of large amounts of virulent virus to distal airways and alveoli. Such exposure may more closely approximate the conditions of a biological warfare or terrorist scenario, rather than those of natural infection where upper respiratory exposure may be of primary concern.

Wenner postulated that, after intramuscular inoculation of monkeypox virus, there was primary replication at the site of injection, followed by low-grade primary viremia and spread of the virus to the spleen, tonsils, and lymph nodes during the pre-eruptive stage. Secondary replication in the lymphoid tissues was thought to provide the principal source of virus for secondary viremia and the establishment of infection at tertiary sites such as the skin, oral mucosa, reproductive system, and gastrointestinal tract (Cho and Wenner, 1973; Wenner et al, 1968, 1969a). The pathogenesis of monkeypox and smallpox after natural, relatively low-dose aerosol exposure appears to follow a similar, although more direct, course compared with that after parenteral inoculation. Clinical evidence suggests that primary replication occurs directly in lymphoid tissues associated with the throat and neck. Lymphadenopathy, initially affecting submaxillary and cervical nodes, occurs at an early stage of clinical monkeypox in humans (Arita et al, 1985; Jezek et al, 1987). Tonsillitis and sore throat are also common clinical features among human patients (Anonymous, 1997a; Jezek et al, 1987). Variola has been isolated from the cervical and pulmonary lymph nodes of monkeys as early as 1 day after aerosol exposure (Hahon and Wilson, 1960). The presence of virus in the throat of secondary contacts during the incubation period of natural smallpox in humans has also been documented, and it was postulated that pulmonary involvement occurs after primary multiplication in the throat (Paschen, 1932). In contrast, monkeypox virus was not isolated from the throats of baboons inoculated by skin scarification until Day 7 postexposure; 

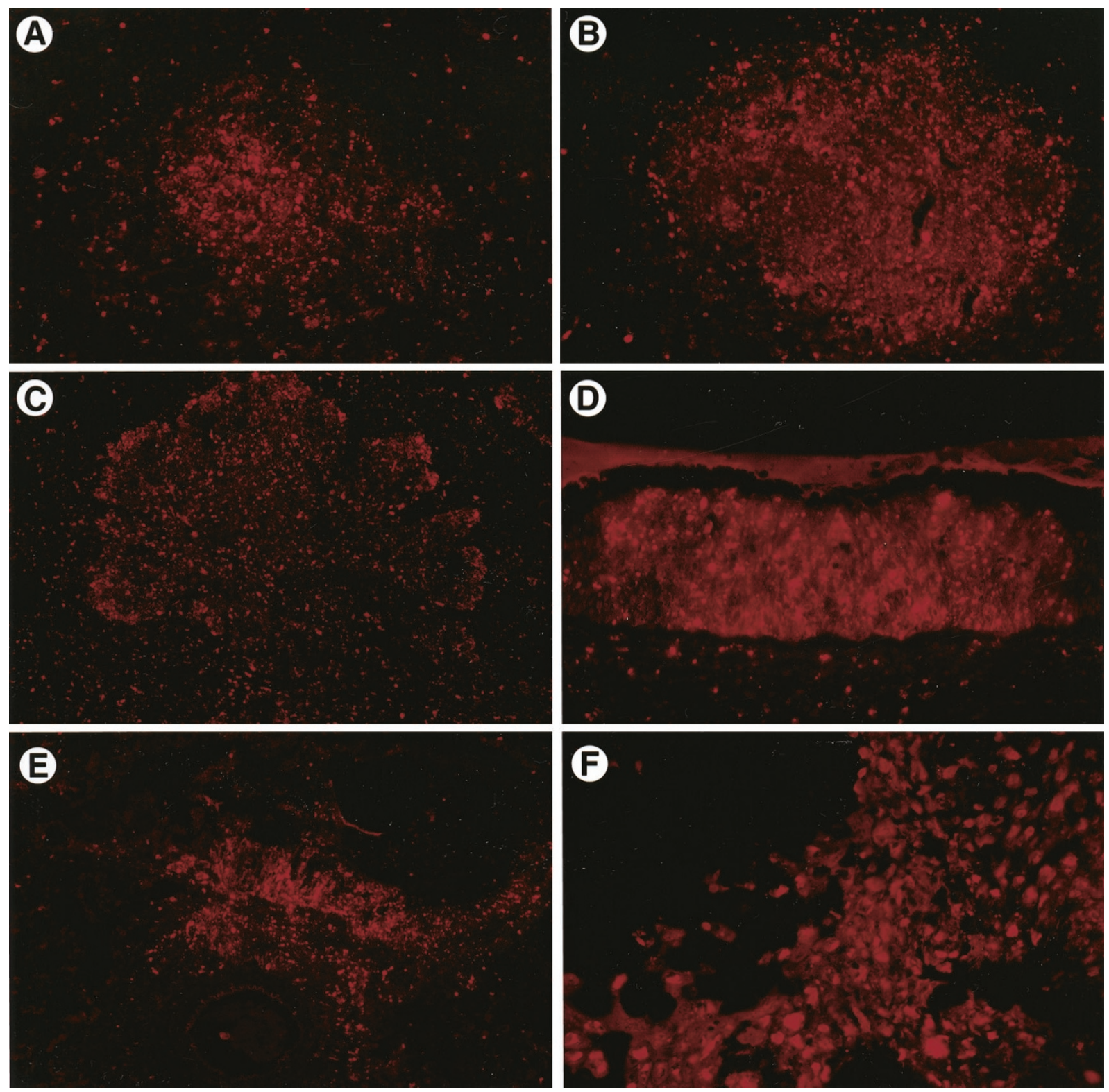

Figure 9.

TUNEL stains illustrating apoptosis in lymphoid and epithelial tissues from monkeypox virus-infected monkeys (A-F). Apoptotic cells are concentrated in necrotic follicular areas of the spleen (A) and colonic gut-associated lymphoid tissues (GALT) (B). Apoptotic cells are distributed throughout a necrotic lobule of thymus (C). Necrotic tracheal epithelium (D), bronchial epithelium and mononuclear cells within the subjacent interstitium (E), and stratified squamous epithelium adjacent to a lip ulcer (F) are all strongly labeled for apoptosis (original magnification, $\times 10[\mathrm{~A}, \mathrm{C}, \mathrm{E}], \times 20[\mathrm{~B}, \mathrm{D}], \times 40[\mathrm{~F}]$ ).

and a poxviral isolate obtained from chimpanzees and variola were not isolated from the throat until Days 3 and 4 postexposure, respectively (Heberling et al, 1976).

Although primary or secondary amplification of monkeypox virus in lymphoid tissues may be essential to systemic dissemination under ordinary circumstances of exposure, our findings suggest that highdose aerosol exposure may result in an abbreviated pathogenesis that appears to parallel that postulated for smallpox in nonhuman primates similarly exposed (Hahon, 1961; Hahon and Wilson, 1960). In our aerosol model, extensive necrosis and large amounts of viral antigen detected in airway epithelia, as well as pulmonary viral titer data, suggest that the airways served as the principal target for primary replication. Primary viremia was most likely the consequence of lymphatic drainage from the lungs through mediastinal lymph nodes and into the thoracic duct. The relative degree of involvement among lymphoid tissues in our study suggests that tonsil, mediastinal, and mandibular lymph nodes were also infected early in the course of the disease and may have served as additional, although subordinate, sites of primary replication. Monocytic cells, immunopositive for poxviral antigen present in pulmonary and mediastinal lymphatics and in sinuses of infected lymph nodes of our monkeys, most likely provided the principal vehicle for lymphatogenous, as well as subsequent hematogenous, dissemination. Our findings are consistent with virologic 
Table 3. Tissue Virus Isolation, Lesion Severity, and Immunohistochemistry from Monkeys Infected with Monkeypox Virus by Inhalation ${ }^{a}$

\begin{tabular}{cccccccccccccccccc}
\hline Animal number & \multicolumn{3}{c}{ Lung } & \multicolumn{3}{c}{ Spleen } & \multicolumn{3}{c}{ Liver } & \multicolumn{3}{c}{ Kidney } & \multicolumn{3}{c}{ Adrenal } \\
\hline 269 & 8.5 & 5 & + & 3.9 & 0 & - & $<$ & 1 & + & 3.4 & 0 & - & $<$ & 0 & - \\
310 & 8.3 & 3 & + & 5.6 & 3 & + & $<$ & 0 & - & 3.5 & 0 & - & $<$ & 0 & - \\
94928 & & 3 & + & 6.9 & 3 & + & $<$ & 0 & - & $<$ & 0 & - & $<$ & 0 & - \\
94735 & 8.1 & 3 & + & 6.2 & 2 & + & $<$ & 0 & - & $<$ & 0 & - & 3.4 & 0 & - \\
94769 & 8.1 & 4 & + & $<$ & 3 & + & $<$ & 0 & - & $<$ & 0 & - & $<$ & 0 & - \\
94961 & 7.9 & 5 & + & 5.3 & 2 & - & $<$ & 0 & - & $<$ & 0 & - & $<$ & 0 & - \\
94813 & 8.9 & 4 & + & 3.9 & 2 & - & $<$ & 0 & - & $<$ & 0 & - & $<$ & 0 & - \\
41125 & 7.9 & 3 & + & 4.5 & 2 & - & $<$ & 0 & - & $<$ & 0 & - & $<$ & 0 & - \\
94962 & 6.9 & 4 & + & 3.9 & 3 & - & $<$ & 0 & - & $<$ & 0 & - & $<$ & 0 & - \\
223 & 7.2 & 3 & + & 4.6 & 2 & + & $<$ & 0 & - & $<$ & 0 & - & $<$ & 0 & - \\
35 & 7.4 & 5 & + & 2.7 & 0 & - & $<$ & 0 & - & 3.2 & 0 & - & $<$ & 0 & - \\
261 & 8.6 & 4 & + & 7.5 & 3 & + & 8.0 & 3 & + & 6.0 & 0 & - & 5.5 & 0 & - \\
330 & 8.2 & 5 & + & 3.2 & 0 & - & 2.9 & 0 & - & 3.2 & 0 & - & 3.5 & 0 & - \\
326 & 7.7 & 4 & + & $<$ & 0 & - & $<$ & 0 & - & $<$ & 0 & - & $<$ & 0 & - \\
289 & 8.2 & 5 & + & 8.4 & 3 & + & 7.6 & 2 & + & 6.2 & 0 & - & 6.7 & 0 & - \\
\hline
\end{tabular}

${ }^{a}$ Data are presented as tissue viral titer $\left(\log _{10} \mathrm{PFU} / \mathrm{g}\right.$ tissue), histopathologic severity $(1=$ minimal, $5=$ severe $)$, and immunohistochemistry result $(+/-)$.

${ }^{b}<$ Indicates viral titer below the detectable limit of $1.7 \log _{10}$ PFU/g tissue.

results from earlier vaccinia, rabbitpox, and variola studies in which viral titers in lung tissues increased exponentially during the incubation period after aerosol exposure, implicating the lung as the site of primary replication (Hahon, 1961; Hahon and Wilson, 1960; Westwood et al, 1966). A recently developed cowpox model in mice, with histologic, immunohistochemical, and virologic findings similar to our own, also supports the belief that pulmonary tissues serve as the primary site for viral replication after aerosol exposure (Bray et al, 2000; Martinez et al, 2000). The significance of secondary replication in the spleen before spread to tertiary sites, as suggested by Wenner with respect to parenteral inoculation (Wenner et al, 1969a), is questionable as it relates to high-dose inhalational exposure. Although we isolated virus from the spleen in $87 \%$ of our monkeys, splenic titers were generally several logs lower than those obtained from lung. Only $73 \%$ of our monkeys exhibited splenic lesions attributable to monkeypox, and lesions were typically mild when compared to the $100 \%$ incidence of moderate-to-severe pulmonary lesions. The spleen was immunoreactive for poxviral antigen in only $47 \%$ of our monkeys, whereas lung was positive in all cases. The pathogenesis after aerosol exposure, therefore, may more closely simulate some aspects of the disease in humans, where splenic involvement is an unusual finding (Muller et al, 1988).

With few exceptions, systemic lesions indicating viral dissemination to secondary or tertiary sites were similar to those seen after experimental parenteral inoculation and natural infection (Gispen et al, 1967; Hahon, 1961; Sauer et al, 1960; Wenner et al, 1968, 1969a). Based on IHC and ultrastructural examination, viral distribution was limited to sites exhibiting morphologic changes readily apparent by routine light microscopy. However, inconsistent immunoreactivity in the spleen, despite the presence of characteristic lesions and detectable tissue viral titers, suggests the possibility of infection below the sensitivity of the immunohistochemical technique. Additionally, no lesions or poxviral immunoreactivity occurred in any of the examined kidney or adrenal gland sections, yet virus was isolated from those areas at necropsy in several monkeys. Monkeypox virus was previously isolated from the kidneys of a chimpanzee and monkeys with clinical disease during spontaneous outbreaks (Marennikova et al, 1972; von Magnus et al, 1959). Variola was isolated from the urine of persons convalescing from smallpox and from the kidneys of experimentally infected macaques (Hahon and Wilson, 1960; Marennikova et al, 1972).

Our study suggests that the mononuclear phagocyte system and associated dendritic cells provide the principal viral targets within lymphoid tissues. Within mildly affected lymph nodes, we detected poxviral antigen in macrophages, dendritic cells, and reticular cells in superficial cortical regions receiving afferent lymph from the subcapsular sinus, suggesting that these cells serve as the initial target or means of introduction of the virus into the node. Infection appeared to progress along the reticular-cell network to involve deeper regions of the cortex and macrophages or dendritic cells in the medulla of more severely affected nodes. Viral antigen was distributed throughout mediastinal and mandibular lymph nodes in advanced stages of necrosis; however, lymphoid necrosis and depletion appeared to have occurred secondarily, without direct viral infection of lymphocytes. Similarly, in the thymus, infected macrophages were occasionally present in areas not yet exhibiting degenerative changes, implicating the macrophage as the initial target or the means of introduction of virus into the tissue. In thymic foci exhibiting minimal necrotic change, infected dendritic cells as well as macrophages were present. Antigen appeared to be concentrated in dendritic cells and macrophages throughout more extensive areas of necrosis. Epithe- 
lial cells of Hassall's corpuscles appeared to have become infected secondarily, whereas lymphocytes remained negative for viral antigen. Involvement of macrophages, dendritic cells, and fibroblasts or reticular cells was a feature also shared by the spleen, tonsils, and GALT.

Distribution of the mononuclear phagocyte system may play a role in determining sites of predilection for tertiary involvement. Many of the secondary and tertiary sites of infection possess significant phagocytic or dendritic cellular components. Langerhans cells of the skin, oral mucosa, lymph nodes, thymus, and tonsils; dendritic cells and macrophages of the lymph nodes, thymus, spleen, and GALT; hepatic Kupffer cells; and reticular cells of the bone marrow are a few noteworthy examples (Cheville, 1994). Poxviral antigen and necrotizing changes in the GALT appeared to precede mucosal epithelial involvement in the intestinal tract. Intestinal lesions also occurred most commonly in regions rich in GALT, further highlighting the importance of the mononuclear phagocyte system in dissemination of the virus to those areas.

Circulating monocytic Langerhans cell precursors could provide the vehicle for introducing virus into stratified squamous epithelia that lack a closely associated lymphoid tissue analogous to GALT. Langerhans cells are known to be susceptible to infection by vaccinia after cutaneous exposure and are believed to provide a vehicle for initial systemic transport of a number of viruses as the dendritic cells emigrate from exposed skin or mucosal surfaces to regional lymph nodes (Nagao and Inaba, 1976; Sprecher and Becker, 1988). We suggest a reciprocal event, whereby monocytic Langerhans cell precursors may carry systemically circulating virus into the skin and oral mucosa. Precursors of Langerhans cells originate in the bone marrow (Katz et al, 1979) and circulate as a subpopulation of monocytic cells in the blood stream before eventual distribution to areas including epidermis and oral mucosa (Bani and Giannotti, 1989; de Fraissinette et al, 1988; Ebner et al, 1998; Hoefsmit et al, 1982; Reid et al, 1990; Rowden et al, 1992; Strunk et al, 1997; Tamaki and Katz, 1980). The viremia of monkeypox is known to be leukocyte-associated (Cho and Wenner, 1973; Wenner et al, 1969b), and, based on our identification of circulating immunopositive monocytic cells in tissue section, appears more specifically to be monocyte-associated. Degenerative changes and detection of viral antigen in oral squamous epithelium progressed superficially from initial involvement of the basal layers. Such a progression would be expected as infected monocytic cells immigrate into the mucosal epithelium. Initial involvement of the submucosa or dermis, with secondary extension into the overlying epithelium, is unlikely, because poxviral antigen was generally not detected in submucosal/ dermal fibroblasts or macrophages in the absence of extensive involvement of the overlying epithelium. Although not definitively identified, weakly immunopositive mononuclear cells associated with unaffected squamous epithelium of the oral mucosa and stomach serve as likely candidates for the vehicle of initial viral entry into the epithelium.

As in humans (Muller et al, 1988), hepatic involvement was unusual in our cynomolgus model. Virus was isolated from the liver of only $20 \%$ of our monkeys. Disseminated hepatitis occurred in $13 \%$ of our monkeys, whereas a single additional monkey exhibited minimal focal hepatitis. Morphologic and immunohistochemical findings among these monkeys indicated that Kupffer cells were the most likely site for initial hepatic involvement, further reinforcing the importance of the mononuclear phagocyte system in dissemination of the disease. In the first monkey with disseminated hepatitis, Kupffer cells were strongly immunoreactive for poxviral antigen, whereas hepatocytes exhibited only mild degenerative changes and minimal immunoreactivity. In the second monkey with more severe hepatic lesions, hepatocellular degeneration was evident throughout examined sections, but poxviral immunoreactivity of Kupffer cells still far exceeded that of affected hepatocytes. These findings, coupled with those of the lymphoid tissues and gastrointestinal tract, suggest that the mononuclear phagocyte system serves as the principal target for systemic dissemination of monkeypox virus infection.

Examination of representative lesions using a TUNEL assay suggested that necrotic changes visualized on routine hematoxylin and eosin-stained tissue sections were due in large part to apoptosis, as opposed to oncosis. Significant apoptotic labeling was limited to areas exhibiting morphologic lesions and was similar to the distribution of viral antigen as detected by IHC.

Concurrent bacterial infection in one of our monkeys appeared to have significant impact on viral dissemination and the clinical course of the disease. Whether the bacterial infection was a pre-existing primary infection or whether it was newly acquired, secondary to monkeypox, is uncertain. Normal preexposure hematological and serum biochemical values and the absence of clinical symptoms until after monkeypox exposure favor the latter; however, the possibility of a pre-existing latent bacterial infection, with exacerbation by subsequent monkeypox infection, cannot be completely excluded. In either case, the affected monkey died on Day 9 postexposure, the earliest time point at which deaths occurred. This monkey was one of only two to develop significant hepatic involvement. High viral titers were detected in liver, kidney, and adrenal gland, and this was the only monkey where splenic viral titers exceeded those of lung. Furthermore, among the 11 monkeys with splenic involvement, lesions and detectable poxviral antigen were generally confined to follicular germinal centers. In contrast, necrotic foci and large amounts of poxviral antigen were disseminated throughout all regions of the spleen in this animal. Finally, this was also the only monkey to exhibit bone marrow involvement. Concurrent illness plays a significant role in determining the clinical outcome of monkeypox in human patients (Jezek et al, 1987). Pretreatment with antilymphocyte serum can adversely affect the out- 
come of subsequent experimental monkeypox virus infection in cynomolgus monkeys, resulting in secondary bacterial septicemia and a $100 \%$ fatality rate (Wenner et al, 1969b). Recruitment of circulating poxvirus-infected monocytic cells to sites of bacterial infection may enhance transport of virus to sites that, otherwise, would be only rarely or mildly affected. Pre-existing infiltrates of mononuclear phagocytic cells at sites of bacterial infection might also result in increased sequestration of the virus to those areas. The occurrence of pre-existing or secondary bacterial infection may be most significant in that low-dose viral exposures, which might otherwise follow a selflimiting sublethal course, could result in death.

The clinicopathologic features of aerosolized monkeypox in cynomolgus monkeys resemble the reported features of monkeypox and smallpox in humans. Death after high-dose aerosol exposure was attributable to bronchopneumonia, with airway epithelium serving as a principal cellular target. Systemic viral dissemination appeared to occur through a monocytic cell-associated viremia, resulting in lesions affecting the lymphoid tissues, skin, oral mucosa, gastrointestinal tract, reproductive system, and liver. The mononuclear phagocyte system may play a critical role in distribution of the virus to secondary and tertiary sites of systemic infection. Concurrent bacterial infection appeared to exacerbate viral dissemination and accelerate the clinical course of the disease. Regardless of organ involvement, lesions were characterized morphologically as necrotizing, with variable proliferation of epithelial cells and fibroblasts. Necrotic changes appeared to be attributable to apoptosis as opposed to oncosis. Monkeypox viral antigen was limited to tissues exhibiting morphologic lesions and was most prominent within epithelial cells, macrophages, dendritic cells, and fibroblasts of affected tissues. The presence of poxviral antigen, as determined by IHC, appeared to correlate with productive viral infection, as observed by ultrastructural examination.

\section{Materials and Methods}

\section{Monkeys}

In conducting this research, the investigators adhered to the Guide for the Care and Use of Laboratory Animals, prepared by the Committee on the Care and Use of Laboratory Animals of the Institute of Laboratory Animal Resources, National Research Council (NIH Publication No. 86-23, revised 1996). The facilities are fully accredited by the Association for Assessment and Accreditation of Laboratory Animal Care International.

Tissues from eight male and seven female, juvenile to adult, 1.6 to $4.7 \mathrm{~kg}$, cynomolgus monkeys (Macaca fascicularis) that died 9 to 17 days after aerosol exposure to monkeypox virus were examined in this study. The monkeys were nonvaccinated controls used in vaccine efficacy trials. Monkeys were identified by tattoo and were housed individually in stainless steel, nonhuman primate cages in a facility fully accredited by the Association for Assessment and Accreditation of Laboratory Animal Care International. Monkeys were fed twice daily with commercial monkey chow supplemented with fresh fruit. Filtered tap water was provided ad libitum. Automatic light cycles in the animal rooms were set for a 12-hour light/dark photoperiod, with no twilight. Relative humidity was maintained between $40 \%$ and $70 \%$. Before exposure, monkeys appeared clinically normal based on physical examination; had normal hematological and serum biochemical values; tested negatively for simian retrovirus, simian T-cell leukemia virus, and simian immunodeficiency virus; and had no detectable antibody to vaccinia virus. After exposure, the monkeys were observed a minimum of twice daily for clinical signs, and they were sedated with tiletamine-zolazepam combination (3-6 mg/kg, intramuscularly, Telazol, A.H. Robbins, Richmond, Virginia) and bled at 2-to-3 day intervals for hematology, clinical chemistries, serology, and virus isolation. After the onset of clinical signs, animals received buprenorphine hydrochloride $\left(0.01 \mathrm{mg} / \mathrm{kg}\right.$ intramuscularly bid, Buprenex ${ }^{\circledR}$, Reckitt \& Colman Products Ltd., Hull, England) to provide analgesia during the course of infection.

\section{Inoculum}

Monkeypox virus Zaire strain (MPOX-Z, CDC isolate V79-I-005) was originally obtained from a fatally infected human from Zaire in 1979. The virus was isolated from scab material in LLC-Mk2 cells and was passaged once in BSC-40 cells and twice in Vero cells. The inoculum for aerosol exposure was supernatant fluid from infected Vero cells.

\section{Aerosol Exposure}

Monkeys were sedated with tiletamine-zolazepam combination (6 mg/kg, intramuscularly). Tidal volume, respiratory rate, and minute volume were measured using a whole-body plethysmograph and a pulmonary mechanics analyzer system (Model 6, Buxco Electronics, Sharon, Connecticut). The anesthetized monkeys were then exposed to aerosolized virus in $10 \%$ bovine serum as a stabilizer in a modified Henderson headonly exposure chamber (Henderson, 1952; Pitt et al, 1991) contained within a Class III biological safety cabinet (Department of Health and Human Services, 1993). Aerosols with a mass median diameter of 1.2 $\mu \mathrm{m}$ were generated by a three-jet Collison nebulizer (May, 1973) containing appropriate dilutions of virus to achieve aerosol inhaled doses of 10,000 to 141,000 plaque-forming units. The aerosol dose was determined for each monkey by continuous sampling throughout each 10-minute exposure directly from the chamber with an all-glass impinger containing supplemented Eagle's minimum essential medium (EMEM) and an antifoam emulsion (Cown et al, 1957). Viral titers of the impinger suspensions were determined by plaque titration on Vero cells. The aerosol-inhaled 
dose was then calculated from the minute volumes measured during plethysmography.

\section{Necropsy}

A complete necropsy was performed on all animals. Samples of all major organs and tissues from each monkey were collected for histopathologic and immunohistochemical examination and were immersionfixed in $10 \%$ neutral buffered formalin. Select tissues for ultrastructural examination were immersion-fixed in $4 \%$ paraformaldehyde plus $1 \%$ glutaraldehyde in $0.1 \mathrm{~mol} / \mathrm{L}$ Millonig's phosphate buffer.

\section{Histology and Immunohistochemistry}

Formalin-fixed tissues for histology and immunohistochemistry were processed and embedded in paraffin according to established procedures (Prophet et al, 1992). Histology sections were cut at 5 to $6 \mu \mathrm{m}$ on a rotary microtome, mounted on glass slides, and stained with hematoxylin and eosin in a Stainomatic specimen stainer (Sakura Finetek USA, Inc., Torrance, California). Gram stains (Lilly Twort) were performed on select tissues from animal no. 289, where bacilli had been seen on hematoxylin and eosin-stained sections. Replicate sections of all tissues were mounted on positively charged glass slides (Superfrost Plus, Fischer Scientific, Pittsburgh, Pennsylvania) and immunohistochemically stained for detection of viral antigen by a streptavidin alkaline-phosphatase (SAAP) method as previously described (Jaax et al, 1996) or by an immunoperoxidase (IPO) method according to kit procedures (Envision System, DAKO Corporation, Carpinteria, California). For SAAP staining, tissue sections were pretreated with citrate buffer at $97^{\circ} \mathrm{C}$ for 30 minutes, incubated with normal horse serum (serum block) for 20 minutes, and incubated with mouse anti-vaccinia polyclonal antibodies (CON $3 \mathrm{E}-1$ provided by Dr. John Huggins, United States Army Medical Research Institute of Infectious Diseases [USAMRIID], Frederick, Maryland) for 1 hour. Sections were subsequently incubated in biotinylated horse anti-mouse immunoglobulin G (Vector Laboratories, Inc., Burlingame, California) and SAAP complex (Invitrogen, Carlsbad, California) for 30 minutes each. Sections were placed in 6-bromo-2-hydroxyl-3naphtholic acid (Histomark Red, Kirkegaard and Perry, Gaithersburg, Maryland) for 50 minutes for color development. Tissue sections for IPO staining received no pretreatment. After a 5-minute peroxidase block, tissue sections were sequentially incubated with rabbit anti-monkeypox polyclonal antibodies (provided by Dr. John Huggins, USAMRIID) for 30 minutes, with a peroxidase-labeled polymer of anti-rabbit/anti-mouse antibodies for 30 minutes, and with 3,3'diaminobenzidine for 8 minutes for color development. For SAAP and IPO staining, incubations were performed at room temperature in a humidified chamber, and then tissue sections were counterstained with hematoxylin. Negative controls were performed by replacement of the primary antibody with normal se- rum of the same species (normal mouse serum or normal rabbit serum for SAAP and IPO, respectively).

\section{TUNEL Staining}

Select lesions from trachea, lung, mandibular lymph node, mediastinal lymph node, spleen, thymus, lip, and colon were evaluated for apoptosis using a TUNEL stain (ApopTag assay, Intergen, Purchase, New York) as directed by the manufacturer. A pan B cell marker, CD20 (DAKO), was also employed as an aid in identifying architectural landmarks within lymphoid tissues. Briefly, $5-\mu \mathrm{m}$ replicate sections of routinely processed, paraffin-embedded tissues were collected on Superfrost/plus slides (Fisher Scientific, Pittsburgh, Pennsylvania), deparaffinized, and rehydrated through graded alcohols to diethyl procarbonate-treated water (Sigma, St. Louis, Missouri). Sections were treated with $20 \mu \mathrm{g} / \mathrm{ml}$ of proteinase $\mathrm{K}$ for 30 minutes at $37^{\circ} \mathrm{C}$, washed in PBS, and placed in an equilibration buffer for 5 to 10 minutes. Excess equilibration buffer was removed, and sections were treated with reaction buffer containing deoxynucleotidyl transferase mediated enzyme for 1 hour at $37^{\circ} \mathrm{C}$. Sections were rinsed and incubated in the stop solution at room temperature for 10 minutes and washed in PBS. Sections were then incubated in anti-digoxigenin-rhodamine diluted in blocking buffer for 30 minutes at $37^{\circ} \mathrm{C}$. Sections were rinsed in PBS and incubated in normal goat serum for 20 minutes at room temperature. Serum was removed and sections were incubated with the CD20 marker for 1 hour at $37^{\circ} \mathrm{C}$ and rinsed in PBS. Sections were incubated in goat anti-rabbit FITC (Sigma) for 30 minutes at $37^{\circ} \mathrm{C}$. After rinsing in PBS, sections were mounted in an aqueous mounting medium and examined on an Olympus BX fluorescence microscope (Olympus Optical, Lake Success, New York) using a wide-band green filter or a blue-band filter for visualization of TUNEL or CD20 labeling, respectively.

\section{Ultrastructure}

Paraformaldehyde/glutaraldehyde-fixed tissues for transmission electron microscopy were postfixed in $1 \%$ osmium tetroxide in $0.1 \mathrm{~mol} / \mathrm{L}$ Millonig's buffer, rinsed, stained with $0.5 \%$ uranyl acetate in ethanol, dehydrated in graded ethanol and propylene oxide, and embedded in POLY/BED 812 resin (Polysciences, Warrington, Pennsylvania). Additional formalin-fixed tissues from four monkeys were rinsed in Millonig's phosphate buffer and treated as above. Areas to be examined by transmission electron microscopy were selected from $1-\mu \mathrm{m}$ sections stained with toluidine blue. Ultrathin sections were cut, placed on 200-mesh copper electron microscopy grids, stained with uranyl acetate and lead citrate, and examined using a JEOL 1200 EX transmission electron microscope (Jeol Ltd., Peabody, Massachusetts) at $80 \mathrm{kV}$. 


\section{Virus Isolation from Blood and Tissues}

Blood was collected for infectivity assays on Days 3 , 6,9 , and 12 or 13 postexposure. Peripheral blood mononuclear cells were separated from $3 \mathrm{ml}$ of EDTAtreated peripheral blood collected from infected monkeys by centrifugation on Histopaque (Sigma) at 250 $\times g$ for 30 minutes. Cells at the interface were harvested, washed in EMEM with Earl's salts, resuspended in $200 \mu \mathrm{l}$ of EMEM, and stored for at least 24 hours at $-70^{\circ} \mathrm{C}$. Infectious virus in the peripheral blood mononuclear cell suspensions was assayed by counting plaques on Vero cells maintained as monolayers in 6-well plates under agarose, as previously described (Jahrling et al, 1990). Portions of lung, spleen, liver, kidney, and adrenal gland were aseptically collected during necropsy and stored at $-70^{\circ} \mathrm{C}$ until assayed for virus. After thawing, tissues were weighed and ground by mortar and pestle with alundum in $5 \mathrm{~mL}$ of EMEM with $10 \%$ fetal calf serum. Tissue homogenates were centrifuged at $10,000 \times g$ for 15 minutes at $58^{\circ} \mathrm{C}$, and viral titers were determined as mentioned above.

\section{Acknowledgements}

We thank Mr. Neil Davis for gross photographic support, Mr. Jeff Brubaker and Ms. Lynda Miller for histologic preparations, Ms. Denise Braun for electron microscopic preparations, Ms. Kathy Spragle and Ms. Roswita Moxley for immunohistochemical preparations, and Drs. Michael Bray, Mark Martinez, and Kelly Davis for their critical review and advice.

\section{References}

Anonymous (1997a). Human monkeypox in Kasai Oriental, Democratic Republic of Congo (former Zaire). Wkly Epidemiol Rec 72:369-372.

Anonymous (1997b). Human monkeypox in Kasai Oriental, Zaire (1996-1997). Wkly Epidemiol Rec 72:101-104.

Anonymous (1997c). Monkeypox in the Democratic Republic of the Congo (former Zaire). Wkly Epidemiol Rec 72:258.

Anonymous (1998). From the Centers for Disease Control and Prevention. Human monkeypox-Kasai Oriental, Democratic Republic of Congo, February 1996-October 1997. JAMA 279:189-190.

Arita I, Gispen R, Kalter S, Wah L, Marennikova S, Netter R, and Tagaya I (1972). Outbreaks of monkeypox and serological surveys in nonhuman primates. Bull World Health Organ 46:625-631.

Arita I and Henderson D (1968). Smallpox and monkeypox in non-human primates. Bull World Health Organ 39:277-283.

Arita I, Jezek Z, Khodakevich L, and Ruti K (1985). Human monkeypox: A newly emerged orthopoxvirus zoonosis in the tropical rain forests of Africa. Am J Trop Med Hyg 34:781789.

Bani D and Giannotti B (1989). Differentiation of interdigitating reticulum cells and Langerhans cells in the human skin with T-lymphoid infiltrate. An immunocytochemical and ultrastructural study. Arch Histol Cytol 52:361-372.
Blank H and Rake G (1955). Smallpox, cowpox, and vaccinia. In: Viral and rickettsial diseases of the skin, eye, and mucous membranes of man. Boston: Little, Brown, and Company, 97-122.

Bras G (1952). The morbid anatomy of smallpox. Doc Med Geogr Trop 4:303-351.

Bray M, Martinez M, Smee DF, Kefauver D, Thompson E, and Huggins JW (2000). Cidofovir protects mice against lethal aerosol or intranasal cowpox virus challenge. J Infect Dis 181:10-19.

Breman J, Kalisa-Ruti, Steniowski M, Zanotto E, Gromyko A, and Arita I (1980). Human monkeypox, 1970-79. Bull World Health Organ 58:165-182.

Breman J, Nakano J, Coffi E, Godfrey H, and Gautun J (1977). Human poxvirus disease after smallpox eradication. Am J Trop Med Hyg 26:273-281.

Breman JG and Henderson DA (1998). Poxvirus dilemmasmonkeypox, smallpox, and biologic terrorism. N Engl J Med 339:556-559.

Cheville NF (1994). Ultrastructural pathology: An introduction to interpretation. Ames, IA: lowa State University Press, 429-487.

Cho C and Wenner H (1973). Monkeypox virus. Bacteriol Rev 37:1-18.

Cohen J (1997). Is an old virus up to new tricks? Science 277:312-313.

Councilman W, Magrath G, and Brinkerhoff W (1904). The pathological anatomy and histology of variola. $J$ Med Res 11:12-134.

Cown WB, Kethley TW, and Fincher EL (1957). The critical orifice liquid impinger as a sampler for bacterial aerosols. Appl Microbiol 5:119-124.

Crandell RA, Casey HW, and Brumlow WB (1969). Studies of a newly recognized poxvirus of monkeys. $J$ Infect Dis 119: $80-88$.

de Fraissinette A, Schmitt D, Dezutter-Dambuyant C, Guyotat D, Zabot MT, and Thivolet J (1988). Culture of putative Langerhans cell bone marrow precursors: Characterization of their phenotype. Exp Hematol 16:764-768.

Department of Health and Human Services (1993). Biosafety in microbiological and biomedical laboratories. DHHS publication no. (CDC)93-8395. Washington, DC, United States Government Printing Office.

Ebner S, Lenz A, Reider D, Fritsch P, Schuler G, and Romani $N$ (1998). Expression of maturation-/migration-related molecules on human dendritic cells from blood and skin. Immunobiology 198:568-587.

Fenner F (1996). Poxviruses. In: Fields B, Knipe D, and Howley P, editors. Fields virology. Philadelphia: LippincottRaven Publishers, 2673-2702.

Foster S, Brink E, Hutchins D, Pifer J, Lourie B, Moser C, Cummings E, Kuteyi O, Eke R, Titus J, Smith E, Hicks J, and Foege W (1972). Human monkeypox. Bull World Health Organ 46:569-576.

Franz DR, Jahrling PB, Friedlander AM, McClain DJ, Hoover DL, Bryne WR, Pavlin JA, Christopher GW, and Eitzen EM Jr (1997). Clinical recognition and management of patients exposed to biological warfare agents. JAMA 278:399-411. 
Gispen R, Verlinde J, and Zwart P (1967). Histopathological and virological studies on monkeypox. Arch Gesamte Virusforsch 21:205-216.

Gough A, Barsoum N, Gracon S, Mitchell L, and Sturgess J (1982). Poxvirus infection in a colony of common marmosets (Callithrix jacchus). Lab Anim Sci 32:87-90.

Grimley PM, Yang YH, Silverman RH, Davis G, and Hoofnagle JH (1983). Blood lymphocyte inclusions associated with alpha interferon. Lab Invest 48:30A-31A.

Hahon N (1961). Smallpox and related poxvirus infections in the simian host. Bacteriol Rev 25:459-481.

Hahon N and Wilson B (1960). Pathogenesis of variola in Macaca irus monkeys. Am J Hyg 71:69-80.

Hall A and McNulty W Jr (1967). A contagious pox disease in monkeys. J Am Vet Med Assoc 151:833-838.

Heberling R and Kalter S (1971). Induction, course, and transmissibility of monkeypox in the baboon (Papio cynocephalus). J Infect Dis 124:33-38.

Heberling R, Kalter S, and Rodriguez A (1976). Poxvirus infection of the baboon (Papio cynocephalus). Bull World Health Organ 54:285-294.

Henderson D (1952). An apparatus for the study of airborne infection. J Hyg 50:53-68.

Heymann DL, Szczeniowski M, and Esteves K (1998). Reemergence of monkeypox in Africa: A review of the past six years. Br Med Bull 54:693-702.

Hoefsmit EC, Duijvestijn AM, and Kamperdijk EW (1982). Relation between langerhans cells, veiled cells, and interdigitating cells. Immunobiology 161:255-265.

Jaax N, Davis K, Geisbert T, Vogel P, Jaax G, Topper M, and Jahrling $P$ (1996). Lethal experimental infection of rhesus monkeys with Ebola-Zaire (Mayinga) virus by the oral and conjunctival route of exposure. Arch Pathol Lab Med 120: 140-155.

Jahrling P, Geisbert T, Dalgard D, Johnson E, Ksiazek T, Hall W, and Peters C (1990). Preliminary report: Isolation of Ebola virus from monkeys imported to USA. Lancet 335:502-505.

Janseghers L, Matamba M, Colaert J, Vandepitte J, and Desmyter J (1984). Fatal monkeypox in a child in Kikwit, Zaire. Ann Soc Belg Med Trop 64:295-298.

Jezek Z, Grab B, Szczeniowski M, Paluku K, and Mutombo M (1988). Clinico-epidemiological features of monkeypox patients with an animal or human source of infection. Bull World Health Organ 66:459-464.

Jezek Z, Szczeniowski M, Paluku K, and Mutombo M (1987). Human monkeypox: Clinical features of 282 patients. J Infect Dis 156:293-298.

Katz SI, Tamaki K, and Sachs DH (1979). Epidermal Langerhans cells are derived from cells originating in bone marrow. Nature 282:324-326.

Khodakevich L, Szczeniowski M, Manbu-ma-Disu, Jezek Z, Marennikova S, Nakano J, and Messinger D (1987). The role of squirrels in sustaining monkeypox virus transmission. Trop Geogr Med 39:115-122.

Lancaster MC, Boulter EA, Westwood JCN, and Randles WJ (1966). Experimental respiratory infection with poxviruses. II. Pathological Studies. Br J Exp Pathol 47:466-471.
Lourie B, Bingham P, Evans H, Foster S, Nakano J, and Herrmann K (1972). Human infection with monkeypox virus: Laboratory investigation of six cases in West Africa. Bull World Health Organ 46:633-639.

Marennikova S, Seluhina E, Mal'Ceva N, and Ladnyj I (1972). Poxviruses isolated from clinically ill and asymptomatically infected monkeys and a chimpanzee. Bull World Health Organ 46:613-620.

Marennikova S, Shelukhina E, Matsevich G, Ezek Z, Khodakevich L, Zhukova O, Yanova N, and Chekunova E (1989). Monkey pox in humans: Current results. Acta Virol 33:246-253.

Martinez MJ, Bray MP, and Huggins JW (2000). A mouse model of experimental aerosol-transmitted orthopoxviral disease: Morphology of experimental aerosol-transmitted orthopoxviral disease in a cowpox virus-BALB/c mouse system. Arch Pathol Lab Med 124:362-377.

May K (1973). The Collison nebulizer, description, performance and applications. J Aerosol Sci 4:235-243.

McConnell S, Serman Y, Mattson D, Huxsoll D, Lang C, and Yager R (1964). Protection of rhesus monkeys against monkeypox by vaccinia virus immunization. Am J Vet Res 25: 192-195.

Mukinda V, Mwema G, Kilundu M, Heymann D, Khan A, and Esposito $J$ (1997). Re-emergence of human monkeypox in Zaire in 1996. Monkeypox epidemiologic working group (Letter). Lancet 349:1449-1450.

Muller G, Meyer A, Gras F, Emmerich P, Kolakowski T, and Esposito $\mathrm{J}$ (1988). Monkeypox virus in liver and spleen of child in Gabon (Letter). Lancet 1:769-770.

Nagao S and Inaba S (1976). Langerhans cells at the site of vaccinia virus inoculation. Arch Dermatol Res 256:23-31.

Paschen E (1932). Pock diseases. Br Med J 2:957-959.

Pitt M, Fleeman G, Turner G, and Young M (1991). Head-only bioaerosol exposure system for large animals (Abstract). Proc Am Assoc Aerosol Res 7:5.

Prier J and Sauer R (1960). A pox disease of monkeys. Ann NY Acad Sci 85:951-959.

Prophet EB, Mills B, Arrington JB, and Sobin LH, editors (1992). Laboratory methods in histopathology. Washington, DC: American Registry of Pathology.

Reid CD, Fryer PR, Clifford C, Kirk A, Tikerpae J, and Knight SC (1990). Identification of hematopoietic progenitors of macrophages and dendritic Langerhans cells (DL-CFU) in human bone marrow and peripheral blood. Blood 76:11391149.

Rowden G, Colp P, Dean S, Auger F, and Lopes Valle C (1992). Comparative epidermal Langerhans cell migration studies in epidermal and epidermal/dermal equivalent grafts. J Invest Dermatol 99:59S-61S.

Sauer R, Prier J, Buchanan R, Creamer A, and Fegley H (1960). Studies on a pox disease of monkeys. I. Pathology. Am J Vet Res 21:377-380.

Sprecher E and Becker Y (1988). Role of epidermal Langerhans cells in viral infections. Arch Virol 103:1-14.

Stagles M, Watson A, Boyd J, More I, and McSeveney D (1985). The histopathology and electron microscopy of a human monkeypox lesion. Trans R Soc Trop Med Hyg 79:192-202. 
Strunk D, Egger C, Leitner G, Hanau D, and Stingl G (1997). A skin homing molecule defines the langerhans cell progenitor in human peripheral blood. J Exp Med 185:1131-1136.

Tamaki K and Katz SI (1980). Ontogeny of Langerhans cells. J Invest Dermatol 75:12-13.

von Magnus $\mathrm{P}$, Andersen EK, Petersen KB, and BirchAndersen A (1959). A pox-like disease in cynomolgus monkeys. Acta Pathol Microbiol Scand 46:156-176.

Wenner H, Bolano C, Cho C, and Kamitsuka P (1969a). Studies on the pathogenesis of monkey pox. III. Histopathological lesions and sites of immunofluorescence. Arch Gesamte Virusforsch 27:179-197.
Wenner H, Cho C, Bolano C, and Kamitsuka P (1969b). Monkey pox. IV. Modification of disease pattern by antilymphocytic sera. J Infect Dis 120:318-331.

Wenner H, Macasaet F, Kamitsuka P, and Kidd P (1968). Monkey pox. I. Clinical, virologic, and immunologic studies. Am J Epidemiol 87:551-566.

Westwood J, Boulter E, Bowen E, and Maber H (1966). Experimental respiratory infection with poxviruses. I. Clinical, virological and epidemiologic studies. Brit J Exp Pathol 47:453-465. 